r.s. chemical\&

\title{
Improvement of Quality in Publication of Experimental Thermophysical Property Data: Challenges, Assessment Tools, Global Implementation, and Online Support
}

Robert D. Chirico, ${ }^{\mathrm{a}, *}$ Michael Frenkel, ${ }^{\mathrm{a}}$ Joseph W. Magee, ${ }^{\mathrm{a}}$ Vladimir Diky, ${ }^{\mathrm{a}}$ Chris D. Muzny, ${ }^{\mathrm{a}}$ Andrei F. Kazakov, ${ }^{a}$ Kenneth Kroenlein, ${ }^{a}$ Ilmutdin Abdulagatov, ${ }^{a}$ Gary R. Hardin, ${ }^{a}$ William E. Acree, Jr., Joan F. Brenneke, ${ }^{c}$ Paul L. Brown, ${ }^{\mathrm{d}}$ Peter T. Cummings, ${ }^{\mathrm{e}}$ Theo W. de Loos, ${ }^{\mathrm{f}}$ Daniel G. Friend, ${ }^{\mathrm{g}}$ Anthony R. H. Goodwin, ${ }^{\text {h }}$ Lee D. Hansen, ${ }^{\mathrm{i}}$ William M. Haynes, ${ }^{\mathrm{g}}$ Nobuyoshi Koga, ${ }^{\mathrm{j}}$ Andreas Mandelis, ${ }^{\mathrm{k}}$ Kenneth N. Marsh, ${ }^{1}$ Paul M. Mathias, ${ }^{\mathrm{m}}$ Clare McCabe, ${ }^{\mathrm{e}}$ John P. O'Connell, ${ }^{\mathrm{n}}$ Agilio Pádua, ${ }^{\mathrm{o}}$ Vicente Rives, ${ }^{\mathrm{p}}$ Christoph Schick, ${ }^{\mathrm{q}}$ J. P. Martin Trusler, ${ }^{\mathrm{r}}$ Sergey Vyazovkin, ${ }^{\mathrm{s}}$ Ron D. Weir, ${ }^{\mathrm{t}}$ and Jiangtao Wu ${ }^{\mathrm{u}}$

a Applied Chemicals and Materials Division, National Institute of Standards and Technology, Boulder, Colorado 80305-3337, United States

${ }^{b}$ Department of Chemistry, University of North Texas, NT Station, Box 305070, Denton, Texas 76203, United States

${ }^{c}$ Department of Chemical and Biomolecular Engineering, University of Notre Dame, Notre Dame, Indiana 46556, United States

${ }^{\mathrm{d}}$ Rio Tinto Technology and Innovation, 1 Research Avenue, Bundoora, Victoria 3083, Australia

${ }^{e}$ Department of Chemical and Biomolecular Engineering, Vanderbilt University, Nashville, Tennessee 37235-1604, United States

${ }^{\mathrm{f}}$ Department of Process and Energy, Engineering Thermodynamics, Delft University of Technology, Leeghwaterstraat 44,

2628 CA Delft, Netherlands

${ }^{\mathrm{g}}$ National Institute of Standards and Technology, Boulder, Colorado 80305-3337, United States

${ }^{\mathrm{h}}$ Schlumberger Technology Corporation, 150 Gillingham Lane, MD150-2, Sugar Land, Texas 77478, United States

${ }^{\mathrm{i}}$ Department of Chemistry and Biochemistry, Brigham Young University, Provo, Utah 84602, United States

${ }^{j}$ Department of Science Education, Graduate School of Education, Hiroshima University, 1-1-1 Kagamiyama, 739-8524,

Higashi-Hiroshima City, Japan

${ }^{k}$ Department of Mechanical and Industrial Engineering, University of Toronto, 5 King's College Road, Toronto, Ontario, Canada M5S 3G8

${ }^{1}$ School of Mechanical and Chemical Engineering, University of Western Australia, Crawley 6009, Australia

${ }^{\mathrm{m}}$ Fluor Corporation, 3 Polaris Way, Aliso Viejo, California 92698, United States

${ }^{\mathrm{n}}$ Department of Chemical Engineering, Virginia Commonwealth University, 102 Engineers' Way, Charlottesville,

Virginia 22904-4741, United States

${ }^{\circ}$ Laboratoire de Thermodynamique (CNRS \& UBP), Université Blaise Pascal, 24 avenue des Landais, 63177 Aubière, France

${ }^{\mathrm{P}}$ GIR-QUESCAT, Departamento de Química Inorgánica, Universidad de Salamanca, 37008-Salamanca, Spain

${ }^{\mathrm{q}}$ Institute of Physics, Universität Rostock, Wismarsche Str. 43-45, 18051 Rostock, Germany

${ }^{\mathrm{r}}$ Department of Chemical Engineering, Imperial College London, South Kensington Campus, London SW7 2AZ, United Kingdom ${ }^{s}$ Department of Chemistry, University of Alabama at Birmingham, 901 S. 14th Street, Birmingham, Alabama 35294, United States

${ }^{\mathrm{t}}$ Department of Chemistry and Chemical Engineering, Royal Military College of Canada (RMCC), PO Box 17000 STN Forces, Kingston, K7K 7B4, Canada

${ }^{\mathrm{u}}$ Center of Thermal and Fluid Science, School of Energy and Power Engineering, Xi'an Jiaotong University, No. 28,

Xianning West Road, Xi'an 710049, China

ABSTRACT: This article describes a 10-year cooperative effort between the U.S. National Institute of Standards and Technology (NIST) and five major journals in the field of thermophysical and thermochemical properties to improve the quality of published reports of experimental data. The journals are Journal of Chemical and Engineering Data, The Journal of Chemical Thermodynamics, Fluid Phase Equilibria, Thermochimica Acta, and International Journal of Thermophysics. The history of this unique cooperation is outlined, together with an overview of software tools and procedures that have been developed and implemented to aid authors, editors, and reviewers at all stages of the publication process, including experiment continued...

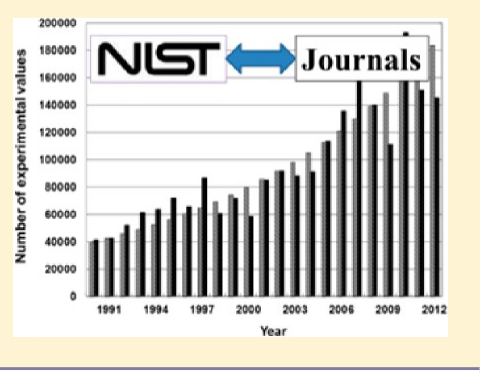

Received: June 14, 2013

Accepted: July 26, 2013

Published: September 6, 2013 
planning. Both successes and failures are highlighted. The procedures are now well established and are designed to yield maximum benefit to all stakeholders (authors, editors, reviewers, publishers, readers, data users, etc.) through the establishment of procedures and support tools that efficiently serve the specific interests of those involved. All specially designed tools and procedures are described fully, together with their benefits and examples of application. A key feature of the cooperation is the efficient validation of experimental data after peer review but before acceptance for publication. Nearly 1000 articles per year are considered within the scope of this work, with significant problems identified in roughly one-third of these. Full statistics for the findings are given, and a variety of examples of common problems found are given.

\section{INTRODUCTION}

This article describes a 10-year effort to improve the quality of published reports of experimental thermophysical and thermochemical property data in the scientific literature. In this article, for the purpose of brevity, the term thermophysical properties represents both thermochemical properties (i.e., properties of reactions, including complete conversion and reaction equilibrium) and traditional thermophysical properties (i.e., properties of nonreacting chemical compounds and mixtures), including all types of phase equilibria and transport properties, such as viscosities and thermal conductivities. This work began in $2003^{1-5}$ and by 2009 had evolved into close cooperation between the editors and publishers of five major journals (Journal of Chemical and Engineering Data, Fluid Phase Equilibria, The Journal of Chemical Thermodynamics, International Journal of Thermophysics, and Thermochimica Acta) and the personnel of the NIST TRC Group (the Thermodynamics Research Center of the U.S. National Institute of Standards and Technology). Within this article, this project is termed the NIST-Journal cooperation. Based on analysis of article content for essentially all journals in this field (i.e., all journals, including those not participating in this cooperation), we estimate that the five cooperating journals, collectively, represent approximately $80 \%$ of the thermophysical property data that are published today.

In a joint statement published in 2009, the editors outlined the need for and goals of the cooperation: "A requirement for submission of a manuscript describing properties is a literature search and comparison of the results with previously reported literature values. Often, reviewers cannot make informed decisions regarding the manuscript because the authors have made only a minimal literature review and comparisons. It is then an unacceptable burden to require reviewers to research previously published literature data to ensure a proper comparison has been made and hence determine the ultimate worth of the manuscript." 6 The statement went on to note that typographic problems and major inconsistencies with the available literature would be summarized in a NIST Data Report provided to the editors, who use this information at their discretion. Within the cooperation, NIST acts strictly in an advisory role, with all accept/reject decisions residing with the editorial staff.

The field of thermophysical property measurements is unusual in modern science, because some experimental data published more than 100 years ago remain of interest today for some engineering applications. Researchers in this field have long recognized the importance of clear and complete reporting of experimental data. The history of efforts to establish datareporting standards, which date to the early 1950s, was summarized recently as part of the IUPAC Guidelines for Reporting of Phase Equilibrium Measurements (2012). ${ }^{7}$ In 1972, the report of the IUPAC project A Guide to Procedures for the Publication of Thermodynamic Data ${ }^{8}$ stated, "The highly interdependent nature of thermodynamic data imposes special obligations upon the author of papers reporting the results of thermodynamic investigations. (The author) must give enough information about (the) experiment to allow readers to appraise the precision and (uncertainty) of (the) results so they may be properly consolidated within the existing body of data in the literature." Words in parentheses were substituted here to bring the text into the 21 st century, but the special obligations described remain today. Although practical and carefully considered, the recommendations of the IUPAC guidelines of $1972^{8}$ were largely ignored, because there was no mechanism for their implementation. The recommendations for documentation requirements were updated and expanded considerably in the IUPAC guidelines of 2012, ${ }^{7}$ with the key difference that today, through use of modern hardware and software tools, we have the ability to ensure their dissemination and implementation.

In this article, we give an overview of procedures that have been implemented in this cooperative work, including both successes and failures. The procedures are now well established and have been designed to yield maximum benefit to all parties involved in the process (i.e., authors, editors, reviewers, publishers, readers, data users, etc.) through establishment of procedures and support tools that efficiently serve the interests of those involved. All tools and procedures are described together with their benefits and examples of application.

Definition of "High Quality" Experimental Data. The importance of thermophysical properties in the development and optimization of chemical process technologies is well established, ${ }^{9}$ particularly with regard to separation methods, such as distillation, extraction, and crystallization. Problems caused by poor quality data include erroneous equipment selections, gross overdesign of plant components, the inability to simulate and discover new processes, poor regulatory decisions, and many others. The word quality is defined as a "degree" or "grade" of excellence. ${ }^{10}$ In a foreword to the Guidelines for Evaluating and Expressing the Uncertainty of NIST Measurement Results of 1994, ${ }^{11}$ then-director of NIST, Dr. John W. Lyons, wrote, "It is generally agreed that the usefulness of measurement results, and thus much of the information that we provide as an institution, is to a large extent determined by the quality of the statements of uncertainty that accompany them." This statement is equally applicable to all reported measurement results. Engineering solutions to industrial and societal problems require property data that are well-defined (i.e., of "high quality") in terms of the chemical system studied, property measured, numerical data reported, and the uncertainty in those reported values.

An additional attribute of high-quality data involves its role in fulfillment of an important industrial or societal need. Repetition of earlier experiments can be justified for many reasons, such as suspected errors, needed lower uncertainties, availability of new high-purity samples, validation of apparatus, etc. Nonetheless, if data for a particular system have been published previously, it is the responsibility of the authors to justify the repetition. In particular, measurements of low uncertainty are not necessarily of high quality if they do not add significantly to scientific knowledge. Tools to aid assessment in this area are described here also. 
Challenges to Achieving High Quality. The largest challenges in the implementation of procedures to aid publication of high quality data arise from the varied and, at times, competing criteria used to judge quality by the various parties involved. Stakeholders include article authors, who are typically university professors, graduate students, postgraduate researchers, and government and industrial laboratory scientists; journal editors, who are also commonly university professors; peer reviewers, who are like the authors by definition; journal publishers; and data users, such as process engineers, model and correlation developers, scientific policy developers, and regulatory agencies. For many of these, the act of publication of a particular article is the primary goal, and subsequent use of the experimental data is of less concern. Degrees are awarded, tenure is achieved, new issues are published, etc. Major users of property data, such as those involved in process design and optimization or correlation and data analysis, are not well represented in the peer-review process. Users involved in environmental health regulation, for example, are typically even less involved.

Exacerbating these problems is the fact that modern journal publishers are known to compete for the fastest submissionto-publication times; perhaps due, in part, to the ease with which this quantity can be measured. In contrast, data quality, as defined above, is very difficult to assess. In some fast shifting and highly competitive fields, speed of publication is a serious concern for proper attribution of credit, but this is very rarely the case in the field of thermophysical properties, where the professional standing of the journal, which is also difficult to measure, is of greatest importance to most authors. Nonetheless, peer reviewers are encouraged to work very quickly and often do not have the time or resources to assess the relevant literature, much less to analyze extensive tables of numerical results for anomalies and inconsistencies. As peer reviewers tend to be drawn from the same pool as authors and editors, they typically reside on the data-producer side of the process, rather than the data-user side, so the motivation to do labor-intensive checks of numerical results is low.

Another major challenge that must be met within all scientific fields is demonstrated in Figure 1. Figure 1 shows the number of experimental data values ("data points") for thermophysical properties that were abstracted by NIST TRC from the five

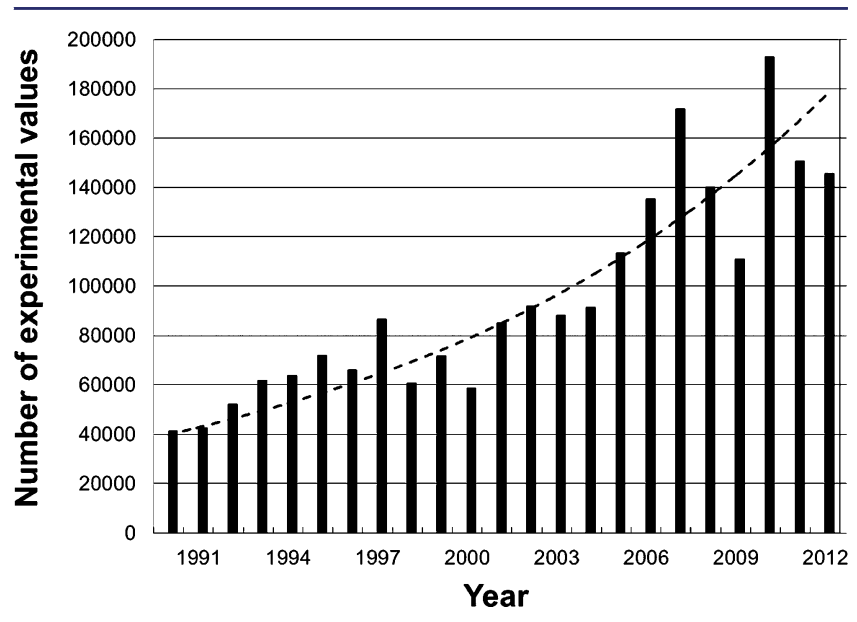

Figure 1. Black bars represent the number of experimental data values for thermophysical properties that were abstracted by NIST TRC from the five cooperating journals in a given year. The dashed curve was calculated based on an increase in the rate of data publication of $7 \%$ per year. journals of this project since 1990 (black bars). The increase in data production is approximately $7 \%$ per year, as demonstrated by the dashed curve. This increase results in a doubling of the rate of numerical data publication every 10 years. Larsen and von Ins ${ }^{12}$ recently analyzed the growth rate in scientific publication for all fields and concluded that (1) the overall growth rate was near $4.7 \%$ per year and (2) the growth rate has not decreased in the last 50 years. The acceleration in data publication for thermophysical properties substantially exceeds that of science in general.

The observed increase in experimental data productivity is supported, in part, by progress in measurement science, including development of high-precision commercial devices for measurement of temperature, pressure, and chemical composition, as well as fully automated control and data acquisition systems for many key properties, such as density, viscosity, heat capacity, etc. In turn, this has led to near elimination of apparatus built in-house in thermophysical-property laboratories worldwide, resulting in a further, and welcome, increase in productivity. Unfortunately, this increase in productivity can be accompanied by a decrease in quality, due, in part, to the fact that automated commercial equipment does not require involvement of personnel with high expertise and in-depth knowledge. This problem is further exacerbated by untenable uncertainty claims made by some equipment manufacturers seeking a competitive edge, which, when combined with a demonstrated $^{13}$ weak understanding within the scientific community of the meaning of uncertainty and its assessment, leads to a prevalence of grossly optimistic uncertainty assessments. If the uncertainties are of poor quality, meaningful application of the results is limited, and the overall utility of the data is lowered substantially.

A review ${ }^{13}$ conducted at NIST TRC of reporting practices for uncertainty of experimentally measured critical temperatures showed that of $\approx 600$ articles published between 1940 and 2001, there was only one ${ }^{14}$ that provided an uncertainty analysis with consideration of all contributing factors, including sample purity. It was also shown that even for articles published after 1990 approximately half reported only repeatability (which is a lower limit for the standard uncertainty) or a manufacturer's claim concerning how well their thermometer might measure temperature, or no uncertainty at all. It is outside the scope of this article to provide examples of appropriate uncertainty analyses, but for the problem of considering sample purity, an approach for one property is demonstrated in the Appendix.

The expression of uncertainty requires clear definition of a variety of quantities and terms, and these were established in 1993 with publication of the Guide to the Expression of Uncertainty in Measurement, ISO (International Organization for Standardization), also known as the GUM. ${ }^{15}$ The ISO recommendations were adopted with minor editorial changes as the U.S. Guide to the Expression of Uncertainty in Measurement. ${ }^{16}$ The recommendations have been summarized in Guidelines for the Evaluation and Expression of Uncertainty in NIST Measurement Results, ${ }^{11}$ which is available via free download from the Internet (http://physics.nist.gov/cuu/). Recently, the full text of the GUM was made available for free download, ${ }^{17}$ as was the International Vocabulary of Metrology (the VIM) ${ }^{18}$ The application of the principles of the GUM to experimental measurement of thermophysical properties was discussed by Chirico et al. ${ }^{19}$ as part of the development of the IUPAC (International Union of Pure and Applied Chemistry) data communication standard, ThermoML. ${ }^{20,21}$ 
Another common source of data quality problems today is erroneous use of modern word processing software. While being a major advance for ease of editing, checking of spelling, formatting of tables, etc., word processing software is also at the root of many published errors that can completely invalidate large data sets. Software functions, such as "cut-and-paste" and "fill-down" in spreadsheets, are extremely convenient, but they also provide the opportunity to create erroneous data rapidly and on a grand scale. Because of this, typographical problems are much worse today than before widespread usage of word processing software (roughly 25 years ago). Typographical problems are common in the older literature, but these tend to be for individual numerical values, rather than errors that invalidate entire data sets, such as the copying of data from one table to another to conserve format, but without updating the numerical values or failing to update compound names. Every year, there is a wide variety of such errors encountered in published articles. Most typographical problems occur in the creation and formatting of the compact tables that conserve space on a printed page but are error prone to create. Such tables must also be deconvoluted (probably back to their original simple form) if they are to be used in any application. The deconvolution process is also error prone. As journals move away from traditional print media to electronic-only form, mechanisms to alleviate this problem should be considered strongly.

In addition to increases in experimental efficiency noted earlier, the increase in productivity shown in Figure 1 is also due to the welcome globalization of scientific efforts. Only 20 years ago, publications originating from South America, much of Asia, Africa, and the Middle East, were relatively rare, and most publications were from North America, Europe, and Japan. This is no longer true. Handling the large number of articles from new and often inexperienced authors is a major challenge for the entire publishing industry. It took multiple generations of researchers to establish protocols for many types of thermophysical property measurements, and in many emerging countries, the mechanisms and educational traditions are only now being established. Global electronic communication can speed the education process, but with so much information available, accessing good information is difficult.

The Peer Review Debate. The traditional peer-review process fails to adequately address many of the problems summarized above. This is largely because it is impossible to independently assess the high volume of presented experimental information within the limited time available for a review. In 2006, the journal Nature conducted a "web debate" concerning peer review that included a series of analyses and perspectives from leading scientists, publishers, and other stakeholders. ${ }^{22}$ Much of the debate centered on fairness and openness of the review process, which is outside the scope of the present article, but some specific recommendations were made that are very relevant to the topic of data quality.

Lee and Bero $^{23}$ provided the commentary, "Increasing accountability: What authors, editors and reviewers should do to improve peer review." The professional background of these authors is in the field of pharmacology, but their comments show a strong parallel to the concerns in the field of thermophysical properties. Two specific recommendations were (1) "Although reviewing raw data can be difficult, time-consuming, and expensive, having such a policy would hold authors more accountable for the accuracy of their data and potentially reduce scientific fraud or misconduct" and (2) "journals should provide specific instructions as well as evaluation tools or checklists for assessing certain types of manuscripts”. Both of these approaches are being taken in the NIST-Journal cooperation for thermophysical properties, and we will show that with development of welldesigned tools, the process does not need to be "difficult, timeconsuming, and expensive."

\section{SCOPE AND STATISTICS}

The scope of the experimental data considered here includes essentially all thermodynamic and transport properties for pure, binary, and ternary chemical systems. Properties of chemical reactions such as enthalpies or thermodynamic equilibrium constants are considered, as well. At this time, properties of molecular and ionic compounds with unique elemental composition, molecular structure, and no overall charge are considered. This means that properties of polymers, clathrates, reactions involving ions (i.e., acid-dissociation equilibrium constants) are not considered here. Of the articles published in the Journal of Chemical and Engineering Data, Fluid phase Equilibria, and The Journal of Chemical Thermodynamics, approximately half of all papers fall within this scope, while for the International Journal of Thermophysics and Thermochimica Acta the fraction is much smaller.

Statistics specific to each participating journal concerning the number of articles published and the number of articles within the scope of this work are given in Table 1. Currently,

Table 1. Average Number Per Year and Fraction of Articles within the Scope of the NIST-Journal Cooperation for Each Participating Journal $^{a}$

\begin{tabular}{|c|c|c|c|}
\hline journal & $\begin{array}{c}\text { articles } \\
\text { published }\end{array}$ & $\begin{array}{l}\text { articles in } \\
\text { scope }^{c}\end{array}$ & $\begin{array}{l}\text { percent in } \\
\text { scope }^{d}\end{array}$ \\
\hline $\begin{array}{l}\text { Journal of Chemical and } \\
\text { Engineering Data }\end{array}$ & 766 & 398 & 52 \\
\hline $\begin{array}{l}\text { The Journal of Chemical } \\
\text { Thermodynamics }\end{array}$ & 271 & 169 & 62 \\
\hline Fluid phase Equilibria & 351 & 125 & 36 \\
\hline Thermochimica Acta & 358 & 76 & 21 \\
\hline $\begin{array}{l}\text { International Journal of } \\
\text { Thermophysics }\end{array}$ & 215 & 16 & 7 \\
\hline sum of all journals & 1961 & 784 & 40 \\
\hline \multicolumn{4}{|c|}{$\begin{array}{l}a_{\text {Table entries are based on the years } 2010 \text { through } 2012 .}{ }^{b} \text { The } \\
\text { average total number of articles published per year. }{ }^{c} \text { The number of } \\
\text { articles within the scope of the cooperation per year. }{ }^{d} 100 \text {. (Articles in } \\
\text { scope/Articles published). }\end{array}$} \\
\hline
\end{tabular}

approximately 2000 articles per year are published by these journals, collectively, with 800 falling within the scope of the cooperation. Many manuscripts are reviewed more than once, plus the overall rejection rate for these journals is roughly $40 \%$, so the number of manuscripts considered is greater than 3000 per year.

\section{HISTORY AND LESSONS LEARNED}

Implementation 1 (2003/2004). The NIST-Journal cooperation was first established with the Journal of Chemical and Engineering Data in 2003, ${ }^{1}$ and this was followed soon after with analogous arrangements with Fluid Phase Equilibria, ${ }^{3}$ The Journal of Chemical Thermodynamics, ${ }^{2}$ the International Journal of Thermophysics, ${ }^{5}$ and Thermochimica Acta. ${ }^{4}$ The focus of this initial cooperation was clarity of data communication and was done at the postacceptance stage in the peer-review process. An early version ${ }^{19,24}$ of what was to become the IUPAC XML-based data communications standard ThermoML ${ }^{20,21}$ had been published, and the NIST ThermoML Archive of published 
experimental data was established. ${ }^{25}$ Authors were "invited" to submit their data through a multistep process by (1) downloading and installing specialized Guided Data Capture software (GDC) $)^{26,27}$ on their computer, (2) using the software to convert their experimental data into a specially formatted file, and (3) submitting the file to NIST by electronic mail. At NIST, the file was (4) checked for errors and completeness, (5) checked for serious inconsistencies with the existing literature using the NIST ThermoData Engine software ${ }^{28-34}$ in conjunction with the NIST TRC-SOURCE Data Archival System, ${ }^{35}$ (6) converted to ThermoML format, and (7) posted on the Web in the NIST ThermoML archive. ${ }^{25}$

The GDC software, which was key to this early effort, serves as a data capture expert by guiding extraction of experimental information from an article, assuring completeness of metadata (properties, phases, constraints, etc.), validating the data through property definitions, range checks, etc., and providing easy-to-use tools for rapid data plotting as a function of any variable, which allows simple detection of many typographical errors. Features of GDC have been described multiple times in the literature. ${ }^{26,27,36}$

The second key tool in this process, the NIST ThermoData Engine (TDE), is expert software that implements the concept of dynamic data evaluation. ${ }^{37}$ This concept requires a large electronic database that stores essentially all related experimental data with complete metadata and uncertainty estimates. For TDE, the associated database is the NIST TDE-SOURCE Data Archive, ${ }^{35}$ which is a version of the NIST TRC-SOURCE database, as described previously. ${ }^{28}$ The combination of this database with the TDE expert software allows generation of critically evaluated data on demand. Complete descriptions of all aspects of the TDE software have been described in a series of articles. ${ }^{28-34}$

As part of the NIST-Journal cooperation, specialized algorithms were constructed within the TDE software to allow automatic generation of a NIST Data Report highlighting inconsistencies between critically evaluated data generated by TDE and new experimental data from a submitted manuscript, together with lists of relevant literature references from the NIST TRC-SOURCE database. At this early stage in the cooperation, the NIST Data Report was used primarily in-house at NIST and was not provided to journal editors. Editors were informed of any serious problems, and authors were directed to submit postpublication corrections, as the manuscript was already accepted. There were many problems with this approach.

The origin of one major problem with this approach lies with the complexity of the thermophysical property data to be communicated. The approach was modeled after the two well-known processes of this type outside the field of thermodynamics: submission and retrieval of crystal structures from the Protein Data Bank (PDB $)^{38}$ and the Cambridge Structural Database (CSD). ${ }^{39}$ These databases are highly successful because only one property (crystal structure) is considered, which allows for data formats that are narrowly defined. It was recognized at the time that establishing a global data delivery process for numerous (>100) thermodynamic properties would be substantially more complex, particularly with consideration of the extensive system of thermodynamic metadata (variables, constraints, phases, methods, uncertainties) required. The Guided Data Capture (GDC) software was designed originally for in-house use by undergraduate chemistry and chemical engineering student working at NIST on various data capture and analysis projects under close supervision. Unfortunately, complexities built into GDC to make it sufficiently flexible to capture a wide variety of data types also made it awkward to use for authors who typically report only a few data types in their entire careers as experimentalists.

A second major problem was that there was little to motivate article authors to participate. As noted earlier, most authors are not major data users and, as such, would have little use for the experimental data in ThermoML format. In practice, nearly all data capture was done in-house at NIST, and of the few GDC files received from authors, the majority required extensive modification to be useful. If the use of GDC had been made mandatory for authors, it is our opinion that this would only have led to high levels of frustration for all involved (particularly authors) and, ultimately, would have led to abandonment of the cooperation effort. A key lesson learned here was that any tools developed must be highly intuitive and unambiguous.

The third, and most important, problem was that the data checking at NIST was being done too late. When authors were invited to participate, the article had already been accepted and changes to the published data could only be made in the form of published corrections or "errata." The process of communicating problems to authors, generating correction documents, keeping editors informed, and journal scheduling requirements, resulted in most corrections appearing in print many months after the original erroneous data were published. By this time, data were already absorbed into the public domain with little likelihood of correction by users. Successes of these early efforts (i.e., the finding of problems in published articles) were touted in $2006,{ }^{27}$ but even then, the problem of wide separation (as much as 3 years) between original publication and correction was apparent.

\section{IMPLEMENTATION 2 (2008)}

The first major redesign of the procedures began with discussions between NIST personnel and journal editors at the International Conference on Chemical Thermodynamics held in Warsaw, Poland, in the summer of 2008. Changes were announced to authors in editorials published in each of the cooperating journals in $2009 .^{6}$

Under the new system, authors were required to provide a Data Summary, which summarized the experimental data reported in each table. The Data Summary included the chemical systems, properties, variables, constraints, experimental methods (brief descriptions), variables, combined expanded uncertainties for properties, and standard uncertainties for variables. The Data Summary was submitted as Supporting Information for review with the manuscript. With the aid of the Data Summary, NIST personnel (1) captured the new experimental data with Guided Data Capture software (described above), (2) generated a NIST Data Report based on the TRC SOURCE database and ThermoData Engine software (described above) that highlighted typographical problems, serious inconsistencies with existing literature, and provided a list of relevant references, and (3) provided the NIST Data Report to the journal editors through the online manuscript handling software of the publisher. The processing time at NIST was typically several working days.

After receipt of the NIST Data Report, editors proceeded with the normal peer review process using the report provided by NIST at their discretion, which could include providing the report to referees to aid the review process or sending the report to authors with an immediate revision request. If changes to the experimental data were required in the review process, authors were expected to notify both the editor and NIST.

As with the earlier implementation of the cooperation, published experimental data were converted to ThermoML format and posted on the Web in the NIST ThermoML 
Archive. ${ }^{25}$ The purpose of the ThermoML format is to facilitate machine-to-machine communications. In order to make the ThermoML files more useful to general users, new and freely available software, ThermoML Opener, ${ }^{40}$ was developed at NIST to allow easy conversion of the stored information into spreadsheet format. ThermoML Opener has also been described in the literature. ${ }^{36}$

While this second implementation of the NIST-Journal cooperation was successful in catching problems with manuscripts early in the review process, several deficiencies became apparent in practice. The largest problem involved the very large effort necessary to get poor manuscripts to even the initial peerreview stage. It was not unusual for poor manuscripts to go through multiple iterations of prereview by NIST personnel, followed by improvement requests from editors, resubmission by authors, followed by another prereview at NIST with more problems, etc. Once the data were finally in acceptable form, the manuscript was often quickly rejected for other reasons, such as poor experiment planning, incorrect model usage, or poor interpretation. When this second implementation was planned, it was believed that manuscripts involving new experimental data would have a much lower rejection rate than other types of manuscript, such as those describing modeling, correlation development, computational chemistry, etc. This proved to be false, with the rejection rate for the cooperating journals being near $40 \%$ of submissions, and with no apparent difference for articles reporting experimental data.

A second problem was that issues highlighted in the NIST Data Report were often not addressed during peer review. Responsibility to check that simple problems were fixed prior to acceptance was often left to the authors themselves, and this approach was found to be unreliable. Overall, this second approach led to far too much wasted effort by NIST staff and journal editors on poor manuscripts at the outset of the review process, plus the failure to correct many problems identified.

Implementation 3 (2010). The second major redesign began with discussions between NIST personnel and journal editors at the International Conference on Chemical Thermodynamics held in Tsukuba, Japan, in the summer of 2010, with changes announced to authors in editorials published in $2011^{41-45}$ Two important changes were made. First, the process was split into two steps with data-checking at NIST occurring only after peer review was complete but prior to acceptance. Second, all cooperating journals agreed to require that authors comply with new (2012) IUPAC recommendations ${ }^{7}$ for the reporting of thermophysical property data. The IUPAC recommendations were established primarily to address documentation issues.

Upon receipt of a submitted article, NIST compiled and provided a new document to editors, the NIST Literature Report, containing relevant references from the NIST TRC-SOURCE database. NIST personnel developed specialized in-house software for this purpose, so that relevant references could be efficiently retrieved based on the chemical system and property or property type, such as "vapor-liquid equilibrium" or "solubility". The NIST Data Report, described earlier, was not generated until the article had successfully passed through peer review but before acceptance. A new term "approved" was coined for an article at this new stage in the review process. Only at this stage were the data abstracted and checked with the Guided Data Capture software and validated with the procedures in the NIST ThermoData Engine. Identified problems were compiled in the
NIST Data Report as before, but these were only for manuscripts that, otherwise, were acceptable.

The emphasis of the NIST Data Report was indication of typographical problems, serious inconsistencies with existing literature, failure to cite or compare with previously published data for the same chemical system and property, and noncompliance with the IUPAC Guidelines for Reporting of phase Equilibrium Measurements (2012). ${ }^{7}$ (The IUPAC recommendations were available online as provisional recommendations in 2011 and were published in 2012.) A key feature of the new requirements was that tables be self-contained and include the uncertainties of all reported quantities (variables, constraints, and properties). To assist authors, numerous example tables were prepared by NIST and made available online. A separate support Web site was created for each participating journal so that the example tables could match the requirements of each journal exactly with regard to format, footnote style, numbering scheme, etc., allowing the authors to use the tables as templates, if desired.

These procedures were in effect through approximately the first quarter of 2013 and were successful in greatly reducing time spent in the review process on poor articles and in catching and repairing many other problems, such as typographical errors, incorrect or incomplete compound identification, incompletely defined data, missing experimental data, and poor uncertainty estimates. Correction after the "approve" stage were necessary for approximately one-third of the articles considered, but only rarely were the problems found to be unfixable, causing the article to be rejected by the journal. It was also found that authors were highly motivated to make corrections at this late stage in the review process, as they recognized these corrections as the only impediment to publication. More discussion of statistics and the types of problems found is given later.

Implementation 4 (2013). The fourth and current implementation of the NIST-Journal cooperation procedures involves an important shift of responsibility for the NIST Literature Report from NIST personnel, at the postsubmission stage, to the authors themselves at the presubmission and even experiment-planning stage. This effort involved development and release of a new software tool ThermoLit ${ }^{46}$ that is freely available on the Web for use by authors, editors, reviewers, data analysts, chemical process designers, etc. In the following section, full details of the current implementation are described. Future work is expected to involve improvements in the quality and scope of the NIST Data Reports and journal support Web sites, but no further fundamental changes in the NIST-Journal cooperation are anticipated.

\section{PROCEDURES ("WORKFLOW") FOR THE NIST-JOURNAL COOPERATION}

The steps now in place for the five journals in the NIST-Journal cooperation are shown in Figure 2. Interaction between NIST and the journals occurs at three distinct stages in the review/ publication process, and these are indicated by large block letters $A, B$, and C in Figure 2. In the following paragraphs, the purpose, functionality, and background of the tools at each stage are described.

Support in Advance of Article Submission (Stage A). At stage A (Figure 2), support is provided to article authors in advance of article submission during both experiment planning (step 1a, Figure 2) and article preparation (step 1b, Figure 2). Tools available to authors on the Web are ThermoLit, ${ }^{46}$ ThermoPlan, ${ }^{50}$ and the journal support Web sites. ${ }^{47}$ These tools are maintained at NIST and are freely available to the public. 


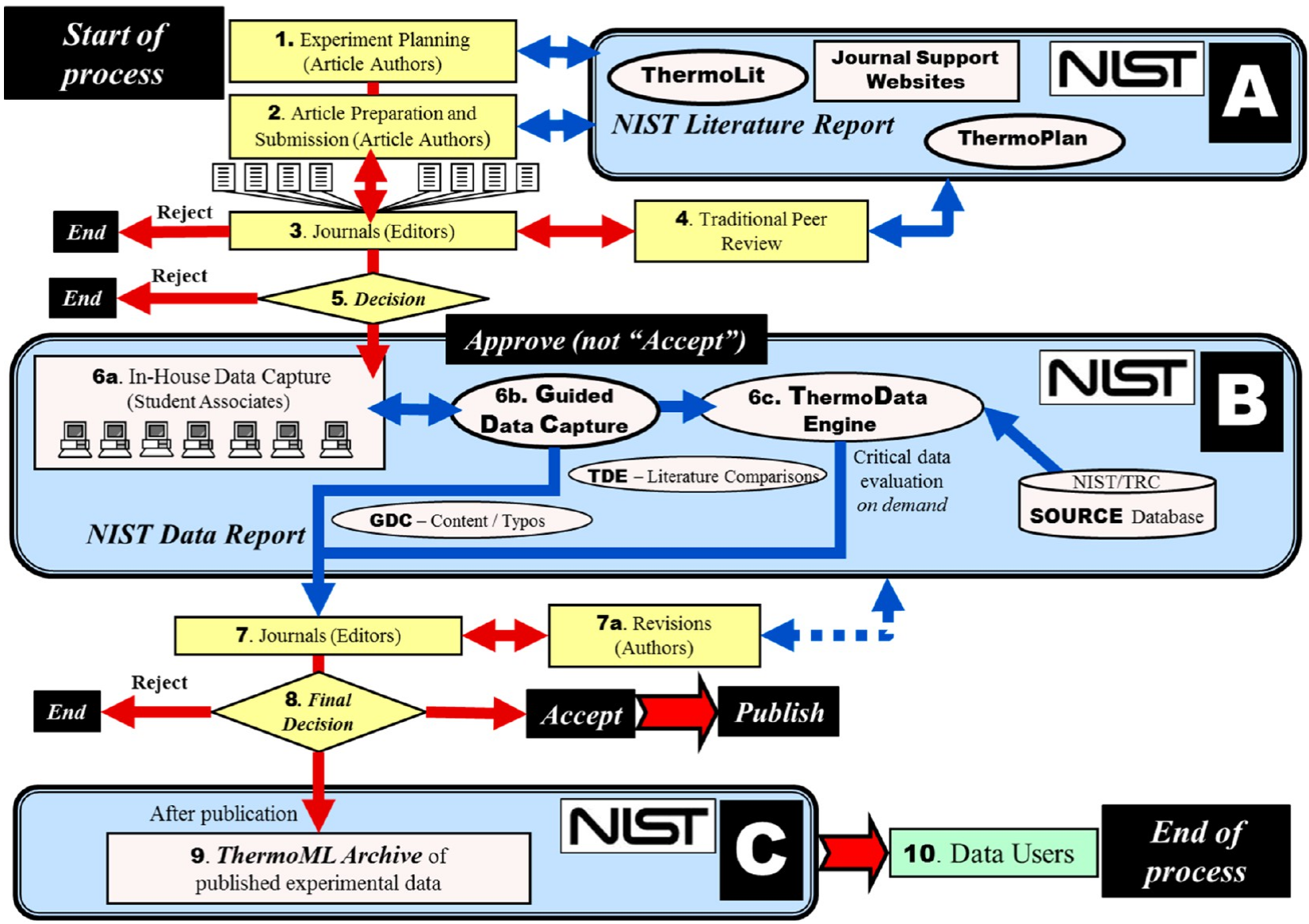

Figure 2. Workflow and tools used within the NIST-Journal cooperation for assessment of thermophysical property data. Sections that involve NIST are indicated with the NIST logo. Roles of authors, editors, and reviewers are indicated by bracketed labels.

ThermoLit is a Web application that provides free and open access to literature information contained in the NIST TRCSOURCE database ${ }^{35}$ and is an easy-to-use tool for generation of a NIST Literature Report in PDF format. The user selects the chemical system type (pure, binary, or ternary), the compounds (based on name, chemical formula, or Chemical Abstracts Service Registry Number) and property (selected from broad categories). The program returns references and variable ranges for the selected property, as stored in TRC-SOURCE. The tool is designed to function like a traditional literature search in that references to properties related to the primary property are also provided. For example, if vapor pressure for the liquid phase is selected, the program will also return references to sublimation pressure data, if any exist. Similarly, if the selected property type is vapor-liquid equilibrium, the program will also return reference information for other types of phase equilibrium, such as liquidliquid equilibrium or solid-liquid equilibrium for the same chemical system. Numerical experimental data are not provided in ThermoLit, as authors are expected to access and cite the primary experimental literature.

Figure 3 shows an annotated screen shot from the ThermoLit Web tool. Compounds selected are stored in a compound cache for access during an active session. Search results are efficiently updated and displayed dynamically as the compounds and properties are changed by the user. Search results may be added to a report draft that can be downloaded by the user and stored locally in PDF format. Short video tutorials (2 to $4 \mathrm{~min})^{48}$ are posted on the Web site to aid the novice user. The brevity of the tutorials is indicative of the efficiency and ease-of-use of the tool.
The ThermoLit tool is intended to aid researchers and reviewers in determining relevant literature sources for a given experimental measurement; however, it is not intended to replace the comprehensive literature review required by all journals, and no guarantee is made regarding completeness of the information provided. The focus of the TRC-SOURCE database is properties of organic compounds of all kinds, but a substantial amount of data for inorganics is included, particularly for solution properties. The scope of chemical-system types covered by ThermoLit is defined clearly on the Web site. ${ }^{49}$ For an analysis of the existing data coverage for a particular property, the web tool ThermoPlan: Experimental Planning and Coverage Evaluation Aid for Thermophysical Property Measurements ${ }^{50}$ is recommended. The complete algorithms underlying the ThermoPlan web tool were described previously, together with implementation in the NIST ThermoData Engine. ${ }^{32}$ The ThermoLit and ThermoPlan Web applications are updated quarterly with the most up-to-date information from the TRC SOURCE archive. At present (April, 2013), TRC-SOURCE contains 4.9 million experimental property values, including those for 21000 pure compounds, 42000 binary mixtures, 11000 ternary mixtures, and 6200 chemical reactions.

Support in Advance of Article Submission (Reporting Guidelines). In 2007, IUPAC project 2007-024-2-100 (Guidelines for Reporting of Phase Equilibrium Data) was initiated by a group of industrial process engineers, data analysts, and journal editors. In 2010, it was recognized that the goals of this IUPAC project and the goals of the NIST-Journal cooperation were essentially the same, and membership of the IUPAC committee 


\section{Measurement System \& Property Selection}

Select System Type:

Help

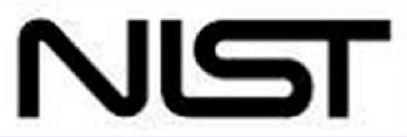

Binary mixture -

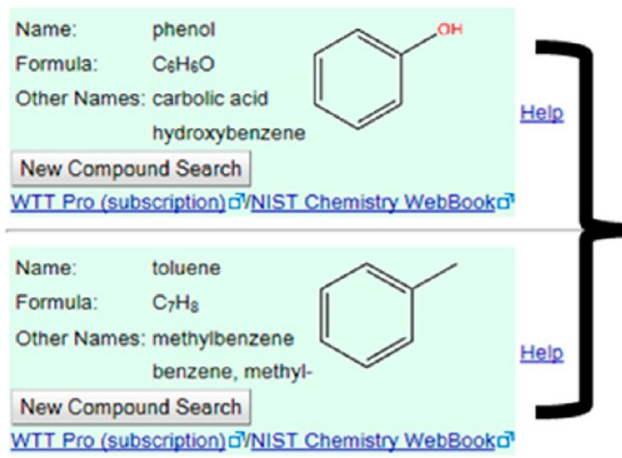

1. Enter compounds:

(pure, binary, or ternary systems)

Select Property:

Property Group: Vapor-liquid equilibria \& solubility

Property: Vapor-liquid equilbria

$-$

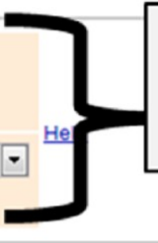

2. Select property:

(broad categories)

\section{Add result to Report Draft}

Compounds: toluene

phenol

Measurement: Vapor-liquid equilbria

4 data sources are listed in the NIST SOURCE Data Archive.

1. Klauck, M.; Grenner, A; Taubert, K: Martin, A; Meinhardt, R: Schmetzer, J. Vapor-Liquid Equilibria in Binary Systems of Phenol or Cresols + Water, + Toluene, an Ind. Eng. Chem. Res., 2009, 47(15), 5119-5126

Temperature: $333.15 \mathrm{~K}-363.15 \mathrm{~K}$

Pressure: $6.89 \mathrm{kPa}-50.97 \mathrm{kPa}$

2. Drickamer, H. G.; Brown, G. G.; White, R. R. Vapor-liquid equilibria in phenol-hydrocarbon systems

Trans. Am. Inst. Chem. Eng., 1945, 41, 555

Temperature: $383.69 \mathrm{~K}-445.92 \mathrm{~K}$

Pressure: $101.32 \mathrm{kPa}$

3. Garner, F. H.; Ellis, S. R. M.

Applicability of vapour-liquid equilibrium relationships to extractive distillation.

Trans. Inst. Chem. Eng., 1951, 29, 45

Temperature: $393.63 \mathrm{~K}-409.23 \mathrm{~K}$

Pressure: $101 \mathrm{kPa}$

4. Nienhaus, B.; Limbeck, U.; Bolts, R.; deHaan, A. B.; Niemann, S.H.; Gmehling, J.

Vapor-Liquid Equilibria at $413.65 \mathrm{~K}$ and Excess Enthalpies at $323.15,363.15$, and 413 J. Chem. Eng. Data, 1998, 43(6), 941-948

Temperature: $413.68 \mathrm{~K}$

Pressure: $29.31 \mathrm{kPa}-210.58 \mathrm{kPa}$

Auxilliary relevant properties and data sources

Measurement: Activity coefficients at infinite dilution

3 data sources are listed in the NIST SOURCE Data Archive.

1. Liu, Y; Greenkorn, R. A; Chao, K.-C

Activity coefficients at infinite dilution. Paraffins, olefins, naphthenes, aromatics, and ch

J. Chem. Eng Data, $1981,26,386$

Temperature: $327.99 \mathrm{~K}-372.97 \mathrm{~K}$

Pressure: $15 \mathrm{kPa}-74.1 \mathrm{kPa}$
3. Program returns:

References from the TRC-

SOURCE collection with

variable ranges

References for related

properties are also provided, as "Auxilliary relevant properties and data sources"

Figure 3. Annotated screen capture of the public ThermoLit Web tool.

was expanded to include editors representing all journals involved in the NIST-Journal cooperation. Recommendations of this committee were published in 2012 as the IUPAC
Guidelines for Reporting of Phase Equilibrium Data (the 2012 Guidelines). ${ }^{7}$ As noted in these recommendations, these were far from the first efforts in this area, as the first such 
recommendations were published in $1972 .{ }^{8}$ A key impediment to full adoption of the previous recommendations was the absence of a mechanism for their broad and targeted dissemination or for their consistent application and enforcement. It was recognized that the NIST-Journal cooperation could provide these missing key elements. The 2012 Guidelines were established as journal policy and were made mandatory for all manuscripts submitted to the cooperating journals. Mechanisms that have been established for their dissemination and consistent application are described below.

A key requirement of the 2012 Guidelines was the creation of stand-alone tables of experimental property data. For many years, journals that publish thermophysical property data instructed authors to create tables that "stand alone"; however, the term was not well-defined and this approach was rarely enforced. Consequently, the reader was often forced to peruse the text for key information, such as the identities of phases, values for constrained variables, definitions of symbols, identities of chemical species, definitions of composition representations, and particularly, for uncertainties. Such disperse reporting ensured that any attempt to incorporate the reported results into the existing body of knowledge was highly error prone.

For the first time, the 2012 Guidelines provided clear descriptions of all requirements for stand-alone tables of experimental property data, together with a variety of example tables ranging from single-property data to complex multiphase equilibria. These examples, and more, were adapted with the specific style requirements for each journal within the cooperation and were posted on journal support Web sites ${ }^{47}$ with full public access. Links to the journal support Web sites are provided to authors by each journal through the Guidelines for Authors included on the journal Web sites. Authors are further reminded to adhere to the table requirements at the revision stage of the publication process, and finally, a check of table content is made at NIST immediately before acceptance.

The 2012 Guidelines include recommendations for titles and abstracts, chemical sample descriptions, and apparatus and experimental procedures, as well as tabulation of experimental results. All recommendations are collected in a Summary Checklist of Documentation Requirements that is included on the journal support Web sites ${ }^{47}$ for access by authors, editors, and reviewers.

Support of the Peer Review Process (Reviewers and Editors). The traditional peer review process is represented by steps 3 through 5 of Figure 2. After submission, manuscripts are handled by the journal editors, who can decide to immediately reject a manuscript based on considerations such as journal scope, quantity of research reported, etc., or can send the manuscript for peer review. Reviewers have full access to the journal support Web sites, ${ }^{47}$ where they can use ThermoLit to help verify that appropriate literature sources have been cited and that appropriate comparisons have been made with published works. The Summary Checklist of Documentation Requirements is also provided to aid the reviewer in ensuring that all reporting requirements are met.

At the end of the peer review process, the journal editors consider the comments of peer reviewers and can reject the manuscript, return the manuscript to the authors for revision, or-within the traditional peer review process-accept the manuscript for publication. It is at this final stage that the process implemented in the NIST-Journal cooperation deviates markedly from the traditional approach. Here (step 5, Figure 2), the manuscript is "approved" but not "accepted" and is forwarded to NIST for analysis. This point marks the end of the traditional peer-review process, and all procedures described from here on do not occur for journals outside of this cooperation.

Support at the "Approve" Stage (Stage B). When a manuscript is "approved" and forwarded to NIST, a series of procedures is carried out (steps $6 a$ to $6 c$, Figure 2) and a summary of the findings (the NIST Data Report) is returned to the journal editor (step 7, Figure 2). Procedures carried out at NIST at this stage have largely been described in the literature, ${ }^{27,51}$ so brief descriptions only are provided here.

On receipt of an "approved" manuscript, NIST personnel identify the experimental data within scope and forward the manuscript to student associates for data capture with Guided Data Capture (GDC) software (step 6a, Figure 2). ${ }^{26}$ The features of the GDC software were summarized earlier along with Implementation 1 of the NIST-Journal cooperation. Student associates are typically chemistry and chemical engineering undergraduate students from the University of Colorado (Boulder, CO) and the Colorado School of Mines (Golden, CO). Data captured by student associates are checked by NIST professionals, and problems (typographical errors, inconsistencies with the 2012 Guidelines, missing or incomplete method descriptions, etc.) are noted in a draft of the NIST Data Report. Special tools were implemented in the GDC software to allow "one-click" exporting of graphs to the report draft, as well as standardized comment text for common problems.

As noted earlier, plotting tools available in GDC are particularly useful in identifying typographical errors in data tables, and an example is shown in Figure 4. The plot shows viscosities reported for a three-component chemical system at four temperatures $T$ between $T=288.15 \mathrm{~K}$ and $T=318.15 \mathrm{~K}$ (pressure $p=0.1 \mathrm{MPa}$ ) for a series of solution compositions. The lines in the figure connect values with the same composition (isopleths), and anomalous data for $T=318.15 \mathrm{~K}$ are apparent. The error was caused by erroneous duplication of columns during manuscript preparation. These data were repaired and the article was accepted. Other examples of typographical problems have been given previously. ${ }^{27,36}$ The GDC software is used to generate an output file of the experimental data from the manuscript in ThermoML format, which serves as input for the NIST ThermoData Engine (TDE), the next piece of software used in the procedures.

As noted earlier, TDE provides critically evaluated thermophysical property data on demand and is used to check for consistency between the newly reported data, data reported previously in the literature, and established prediction methods and correlations. Examples of problems with newly reported data are shown in Figures 5, 6, and 7.

Parts A and B of Figure 5 show deviation plots (percentage and absolute) generated by TDE for vapor pressures of diisopropyl ether that were reported as part of vapor-liquid equilibrium studies for a series of binary mixtures. All deviations are shown relative to values critically evaluated by the TDE software. The black dots in the figures represent experimental data from the literature. The gold dots are also experimental data from the literature, but these were rejected by TDE in the evaluation. (Weighting of experimental and predicted data, data selection/ rejection criteria, models, model fitting, and uncertainty assessment in TDE are described in the articles describing the software. ${ }^{28-34}$ ) Figure 5B shows the reported values to be low by roughly $(-1.2 \pm 0.6) \mathrm{kPa}$, which could be caused by an error in calibration of a pressure-measuring device. The stated standard 


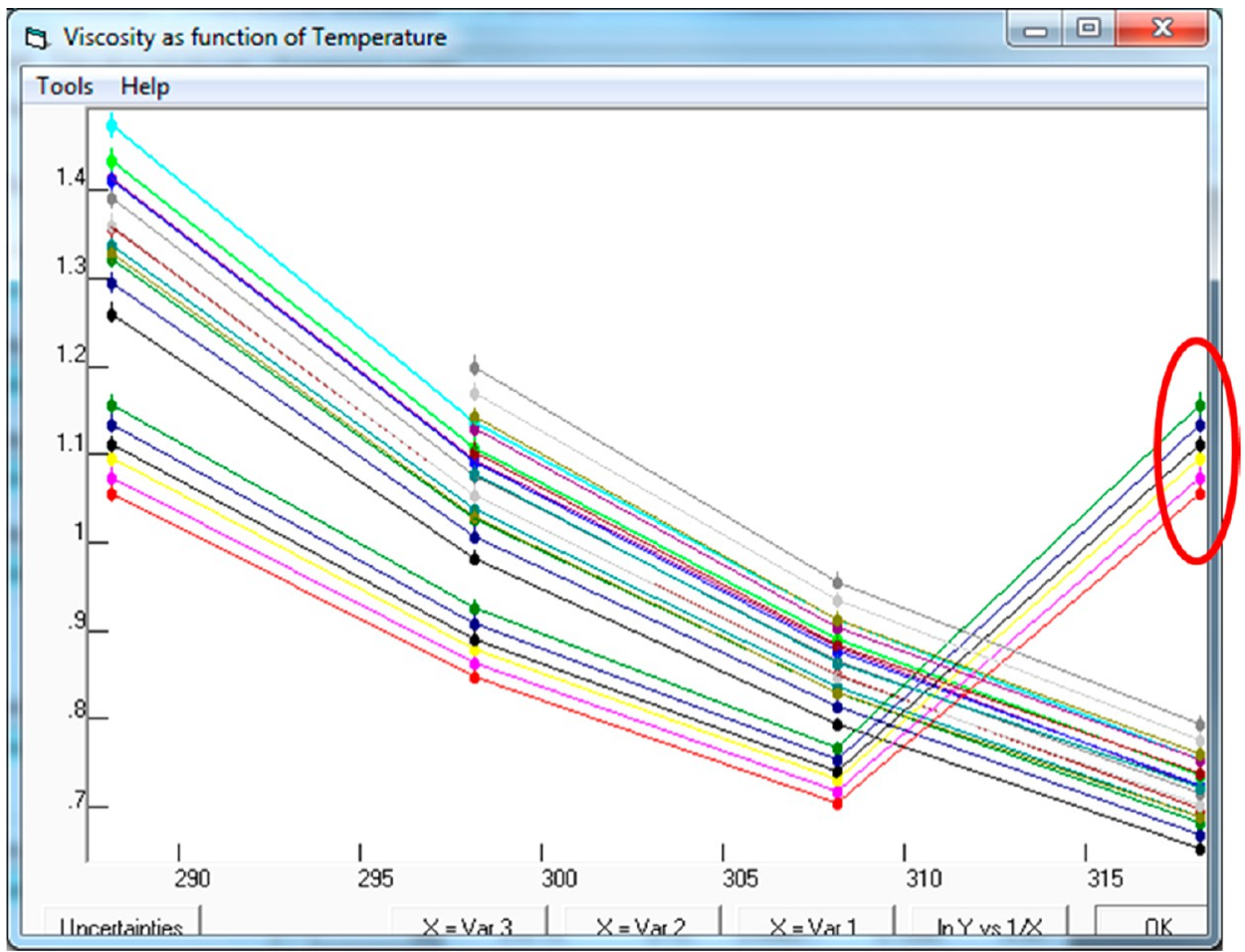

Figure 4. Viscosities (in $\mathrm{mPa} \cdot \mathrm{s}$ ) for a ternary mixture plotted as a function of temperature (in $\mathrm{K}$ ). Lines represent data of constant composition (isopleths). Anomalous data from the submitted manuscript are circled in red.

uncertainty for the pressures was $0.05 \mathrm{kPa}$, which is more than 20 times smaller than the average deviation. This article was rejected by the journal based on these findings.

Parts A and B of Figure 6 demonstrate two types of errors for properties of mixtures. Both examples come from the same manuscript. Here, the property is viscosity and the chemical systems studied were mixtures of cyclohexane with a series of esters. In Figure 6A, the newly reported viscosities, for methyl propanoate for the temperatures $T=298.15 \mathrm{~K}$ and $T=308.15 \mathrm{~K}$ (pressure $p=0.1 \mathrm{MPa}$ ) are shown to be roughly $20 \%$ and $12 \%$ higher relative to values reported in the literature by multiple researchers, while the claimed standard uncertainty for the new data was $1 \%$. A single literature value was cited in the manuscript (indicated by the arrow in Figure 6A) as evidence of good agreement with existing literature values. In fact, this anomalous cited value was reported previously by the submitting authors and is certainly part of the low-quality data already published in the literature. The problems demonstrated for this pure component ensure that property values reported in the manuscript for any mixture involving this component are also invalidated.

Figure $6 \mathrm{~b}$ shows viscosity results at temperature $T=298.15 \mathrm{~K}$ and pressure $p=0.1 \mathrm{MPa}$ for the chemical system (ethyl propanoate + cyclohexane). Multiple literature sources are shown to be in very good agreement (within $2 \%$ ), while the newly measured values show deviations as large as $15 \%$ near the middle of the composition range. Here, the values for the pure components (i.e., mole fractions of cyclohexane at 0 and 1 ) are in good accord with the literature, and the mixture data are anomalous. This manuscript was rejected by the journal based on these findings.

Figure 7 shows a percentage deviation plot for densities of acetone that were reported as part of an extensive study of binary mixtures of acetone with a large series of other compounds. The literature data for acetone are numerous and in good agreement (within $0.2 \%$ ), while deviations for the newly reported values range from $0.4 \%$ low to $0.8 \%$ high). The claimed standard uncertainty was less than $0.1 \%$. The anomalous data may have been caused by errors in calibration of the densimeter, but that cannot be determined based on the reported information. If the new data had been reported at higher temperatures $(T>410 \mathrm{~K})$, they would not have been considered anomalous within the TDE software because the literature data in this region (within the rectangle in Figure 7) are consistent to within only $1.5 \%$. This manuscript was rejected based on these results.

All anomalous data shown in Figures 4 through 7 would have been published in the archival literature if the procedures described here had not been implemented. It is possible that the rejected manuscripts were subsequently accepted by a journal outside of the NIST-Journal cooperation, but this is not known at this time.

A special quality assessment algorithm for binary vapor-liquid equilibrium (VLE) data was developed in 2010 for mixtures involving components at low-pressure $(<1 \mathrm{MPa})$ subcritical conditions. ${ }^{33}$ The algorithm combines four widely used tests of data consistency based on the requirements of the Gibbs-Duhem equation, plus a check of consistency between the VLE data and the vapor pressures of the pure components. The algorithm was subsequently extended to systems involving supercritical components, and the extensions were described together with implementation of the quality assessment algorithms in TDE. ${ }^{51}$ Results of the six tests are given numerical scores that are combined algebraically to yield an overall data quality factor $Q_{V L E}$, which is used in TDE to weight diverse experimental data sets in the fitting of activity coefficient models. A low $Q_{\mathrm{VLE}}$ value can indicate serious problems with reported VLE data, such as errors in units or misidentification of components and phases.

An example of an error identified with the VLE quality assessment algorithm is shown in Figure 8. Experimental VLE data 

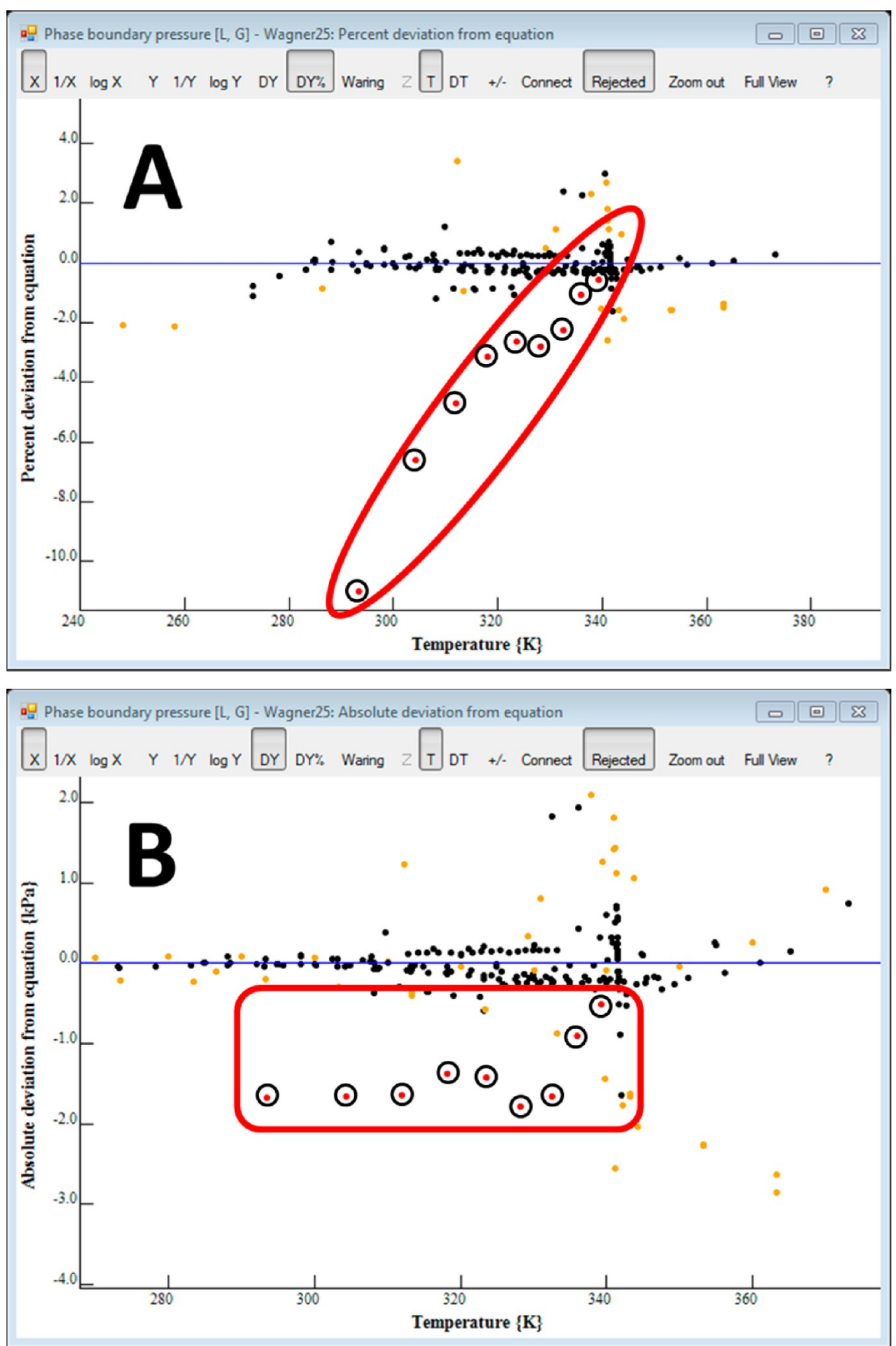

Figure 5. Deviation plots (A, percentage; B, absolute) generated by TDE for vapor pressures of diisopropyl ether reported as part of vapor-liquid equilibrium studies for a series of binary mixtures. Submitted experimental data are circled in the figure.

were submitted for the system (pyrrolidine + water). The $Q_{\mathrm{VLE}}$ value for the data, as submitted, was very low $\left(Q_{\mathrm{VLE}}=0.05\right)$, indicating a problem. Results of the individual data-consistency tests are output by TDE in graphical form to a draft of the NIST Data Report for the particular manuscript. These graphs are inspected by NIST personnel when a problem is indicated. Figure 8a shows the results of the Van Ness test (as described in ref 52) for the experimental data, as first submitted. Plots such as those in Figure 8 provide essential clues to understanding underlying problem sources. In this case, column headings for 

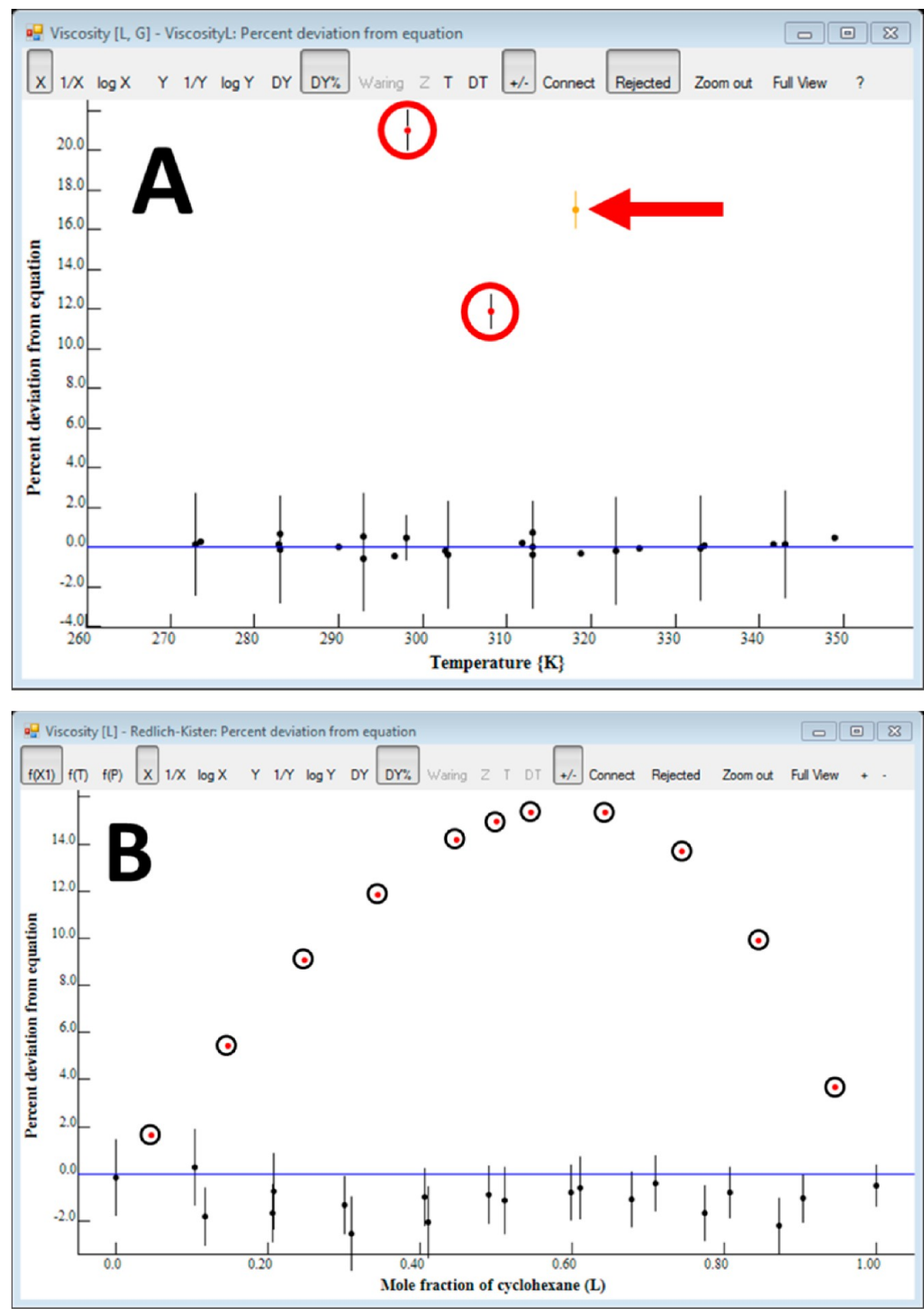

Figure 6. (A) Submitted viscosities for methyl propanoate (circled) relative to literature values reported by multiple researchers (black dots). The arrow indicates the only literature value cited in the manuscript. (B) Submitted viscosities for the system (ethyl propanoate + cyclohexane) (circled). Literature data from multiple sources are shown as black dots.

compositions of the liquid and vapor phases were reversed in the submitted manuscript. The data are shown after correction in Figure $8 \mathrm{~B}$. Once corrected, the quality assessment factor $Q_{\mathrm{VLE}}$ increased to near 0.50 . The data were repaired in the manuscript and the article was accepted by the journal. This problem would not have been detected without application of the dataconsistency algorithm in TDE. Multiple examples of problems discovered through the VLE consistency tests in TDE have been described. ${ }^{51,52}$ All vapor-liquid equilibrium data processed through the NIST-Journal cooperation procedures are checked with these assessment procedures.

At the end of the NIST data-review procedures (stage B, Figure 2), any problems found are communicated to the journal editors in a NIST Data Report for each manuscript that is uploaded through the online editorial system of the publisher (step 7, Figure 2). If needed, the editors communicate with the 


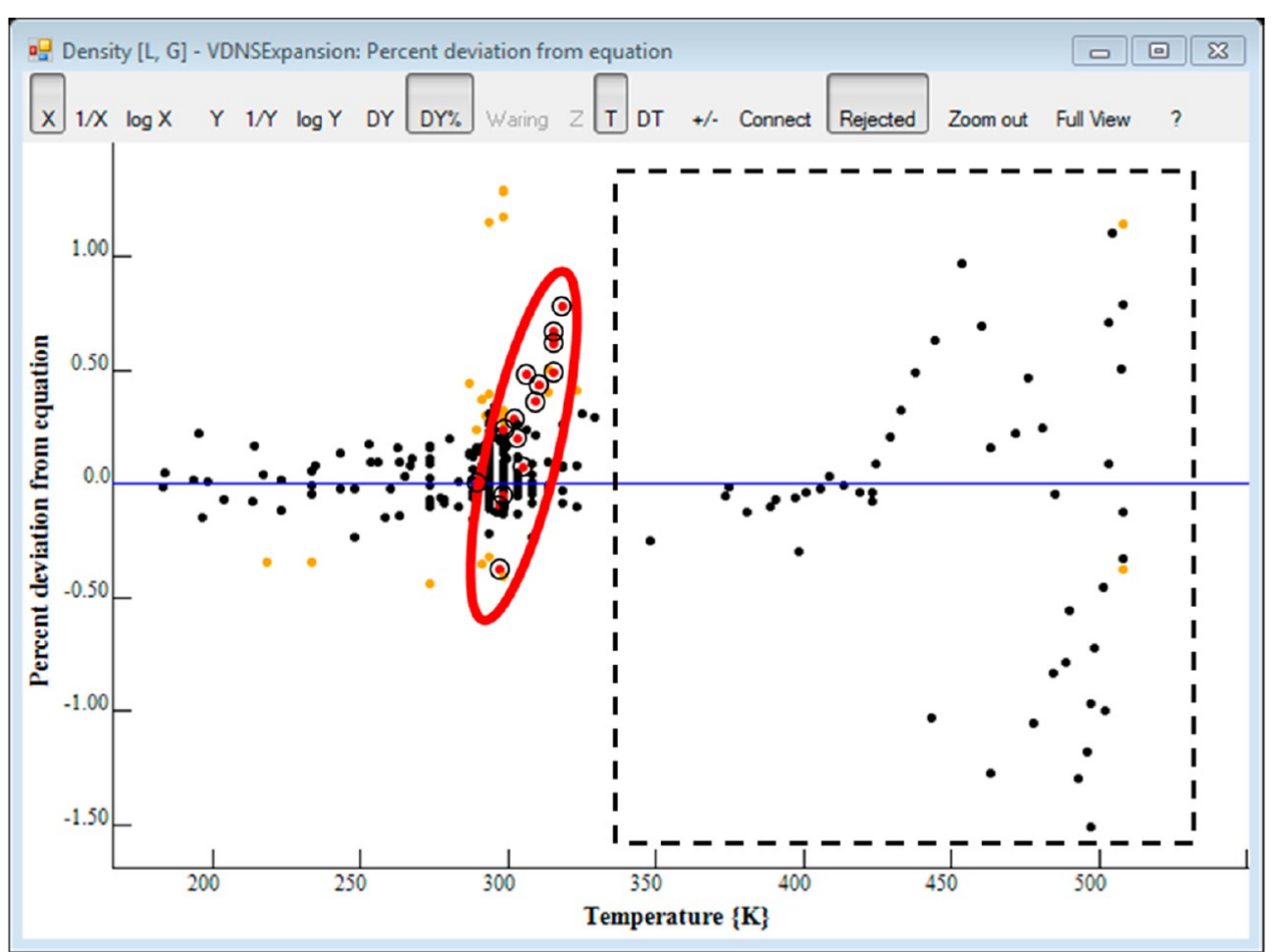

Figure 7. Deviation plot for densities of acetone submitted as part of an extensive study of binary mixtures of involving acetone (circled). Literature experimental data for acetone from multiple sources are shown as black and orange dots. (Data represented as orange dots were rejected in the automated TDE data analysis.) The dotted rectangle indicates data for temperatures above the normal boiling temperature of acetone $(T / \mathrm{K} \approx 329)$, where uncertainties are large.

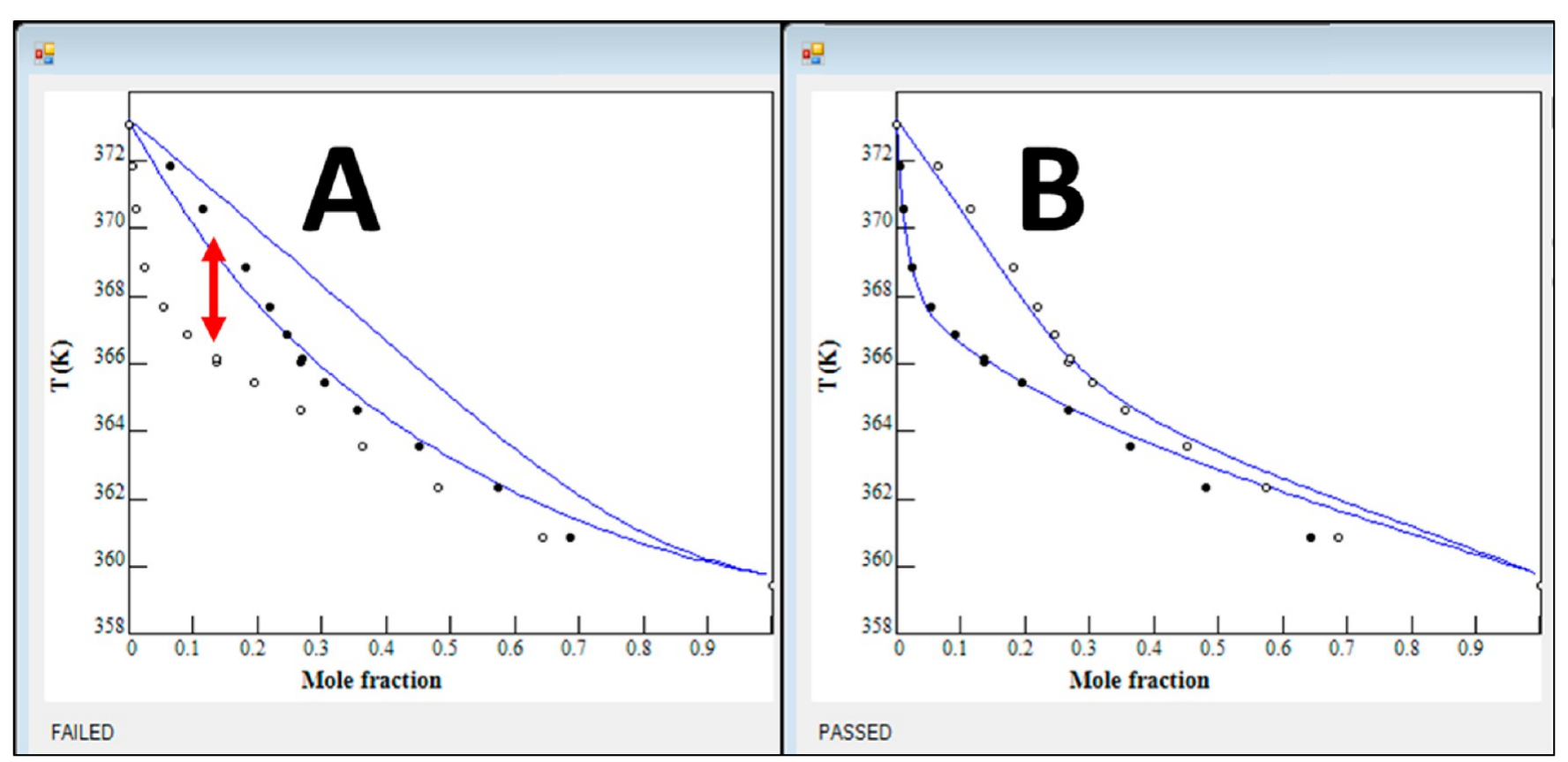

Figure 8. Results of the van Ness test as implemented as part of the VLE quality assessment algorithm in TDE. ${ }^{33,51}$ Experimental VLE data for a mixture of an amine and water are shown as submitted (A) and revised (B). Filled circles represent bubble-point data and open circles are dew points. Compositions for the liquid and gas phase were erroneously switched in the submitted data, as indicated by the double-headed arrow.

authors concerning repair of any problems found. If the experimental data are repaired in a revision, the process is returned to step 5 and a new review of the data is carried out and an updated NIST Data Report is provided for the manuscript. At the end of all reviews and revisions, the editor makes a final decision to accept or reject the manuscript (step 8, Figure 2).
Support for Data Users at the Postpublication Stage.

For accepted manuscripts, the experimental data and metadata are converted to ThermoML format and posted online in the NIST ThermoML Archive ${ }^{25}$ of published experimental data (step 9, Figure 2). This portion of the NIST-Journal cooperation has been in effect since the first implementation in 2003 and has 
been described previously. ${ }^{27}$ The archive of ThermoML files is freely available for download by users (step 10, Figure 2). Applications of the NIST ThermoML Archive as part of a "global information system in science" have been described by Frenkel. $^{36,53}$

\section{STATISTICS FOR TYPES OF PROBLEMS FOUND}

Approximately one-third of articles that are "approved" (i.e, they reach stage $B$ of Figure 2) are found to contain significant problems that require further revision. This portion does not include manuscripts returned to ensure conformity with the recommendations of the IUPAC 2012 Guidelines $^{7}$ with regard to data and metadata to be included in tables of experimental property data. The IUPAC recommendations were established quite recently, and authors are only now adapting to them.

Figure 9 shows statistics concerning the types of problems found in the one-third of manuscripts that require revision.

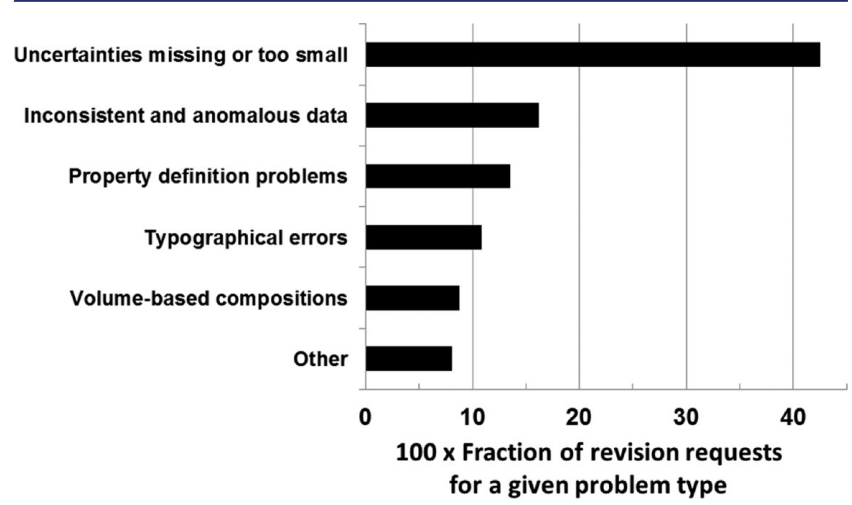

Figure 9. Statistics for types of problems found in one-third of manuscripts at the approve stage (stage B) of the workflow (Figure 2) (i.e., after peer review and before acceptance).
The most common problem is that of missing or grossly underestimated uncertainties. Authors often report manufacturers' claims for particular measuring devices as uncertainty, without consideration of the experimental context or validation. A typical example is shown in Figure 10. The figure shows results of a VLE study for the system (butan-2-ol + methylcyclopentane). The property graphed is pressure as a function of mole fraction of butan-2-ol, and the lines represent isotherms. The stated standard uncertainty for the measured pressures was $0.01 \mathrm{kPa}$, which is more than 10 times smaller than the size of the dots representing the measured values. Based on the observed scatter in the data, the repeatability of these measurements is near $2 \mathrm{kPa}$, which is 200 times larger than the claimed "uncertainty". As noted earlier, the $2 \mathrm{kPa}$ repeatability is only a lower limit for the standard uncertainty because the purity of the samples and other factors have not been considered. Numerous similar examples can be found in the published literature. Uncertainties were appropriately adjusted by the authors, and this manuscript was later accepted by the journal.

The estimation of the contribution of sample impurity to measurement uncertainty is difficult, but it must be addressed if data are to be used effectively in the solution of academic, industrial, and environmental problems. An example of how to estimate the uncertainty contribution for sample impurity in the measurement of density is given in the Appendix.

The second largest fraction of revision requests (Figure 9) is related to data that are inconsistent with the existing literature or show anomalous trends when plotted as a function of a particular variable. An example is shown in Figure 11, where densities of (dibutyl phthalate + ethenyl acetate) are shown as a function of composition for three isotherms. When plotted, such data are generally a series of parallel curves, as seen in the upper left of Figure 11. The densities of the upper curve on the right side of the figure are anomalous. This manuscript was rejected at the approve stage for this reason. Examples of submitted data that were inconsistent with the existing literature were given earlier.

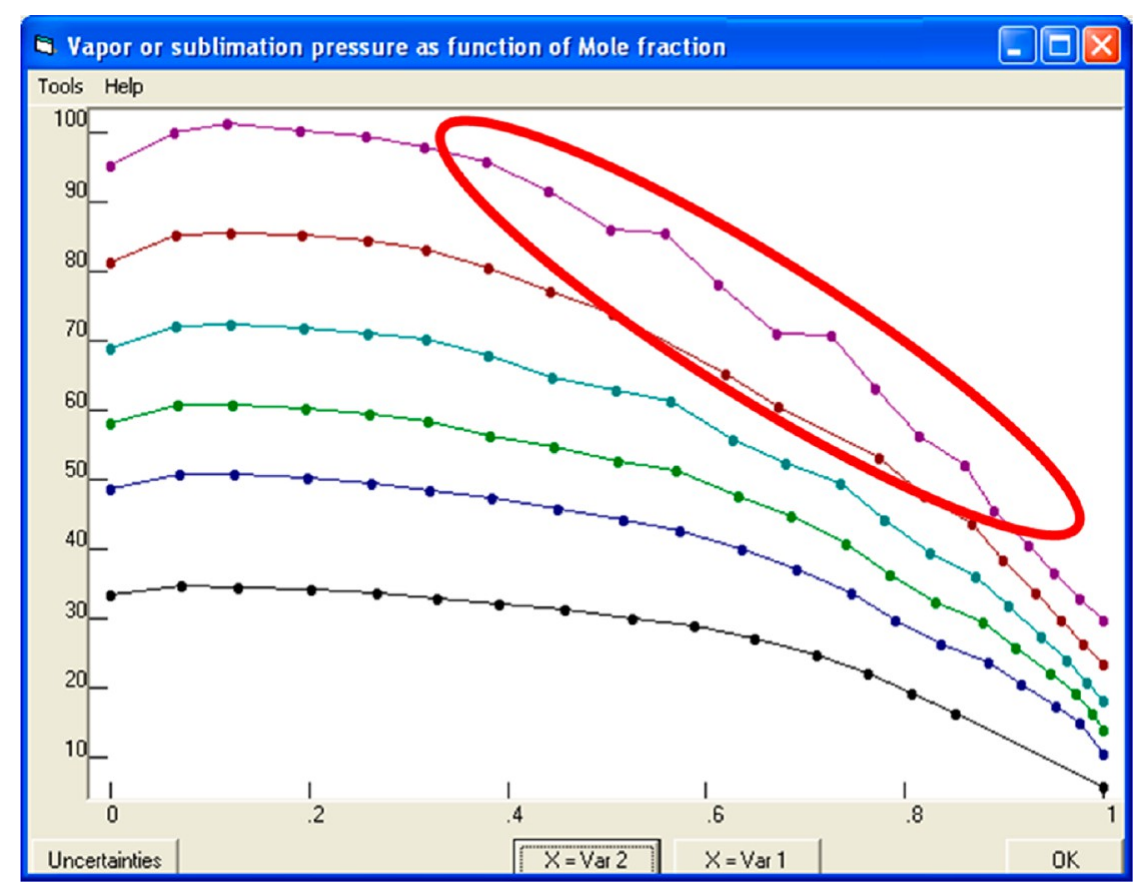

Figure 10. Pressure (in $\mathrm{kPa}$ ) as a function of mole fraction in a VLE study for a binary system of an alcohol with a cyclic alkane. The standard uncertainty stated in the manuscript was $0.01 \mathrm{kPa}$, which cannot be detected on the plot. The repeatability for the circled values is approximately $2 \mathrm{kPa}$. 


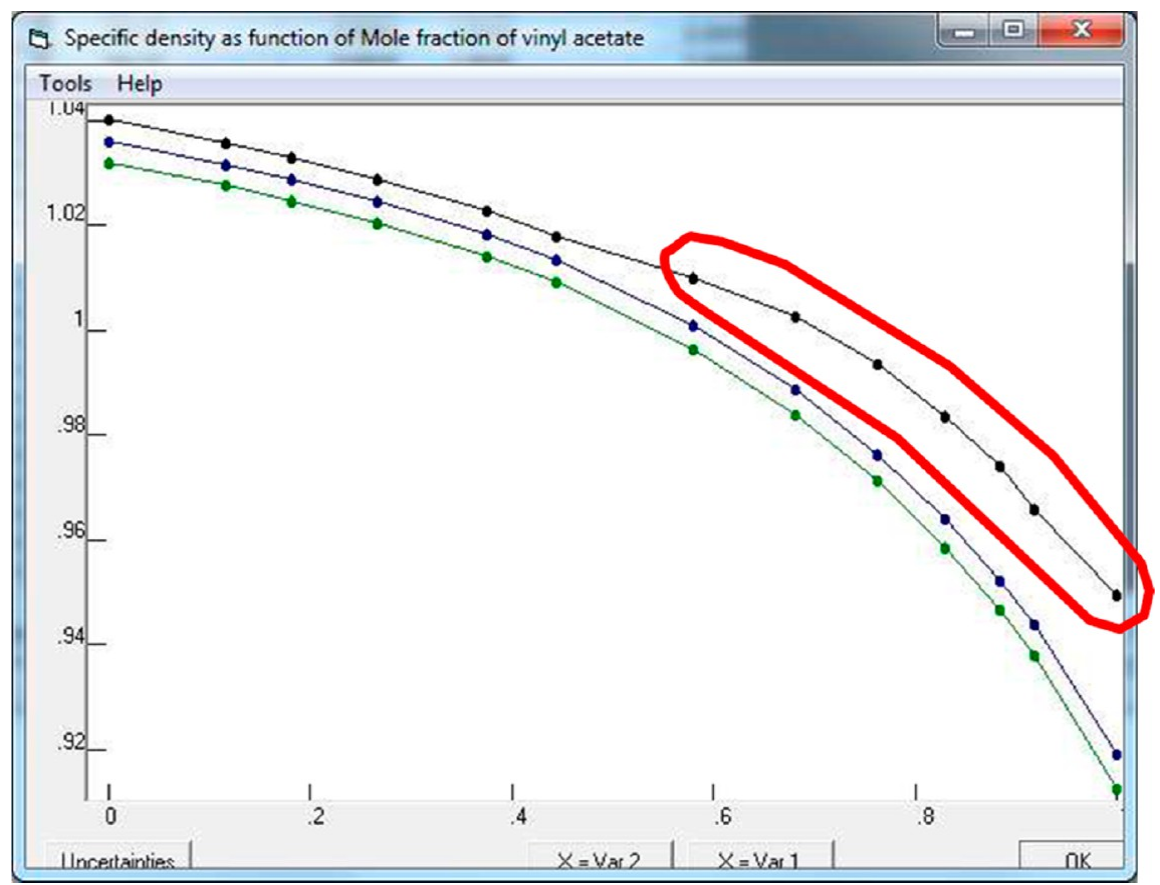

Figure 11. Densities (in $\mathrm{kg} \cdot \mathrm{dm}^{-3}$ ) for the a binary system involving two esters are shown as a function of mole fraction of ethenyl acetate for three isotherms. Anomalous submitted data are circled.

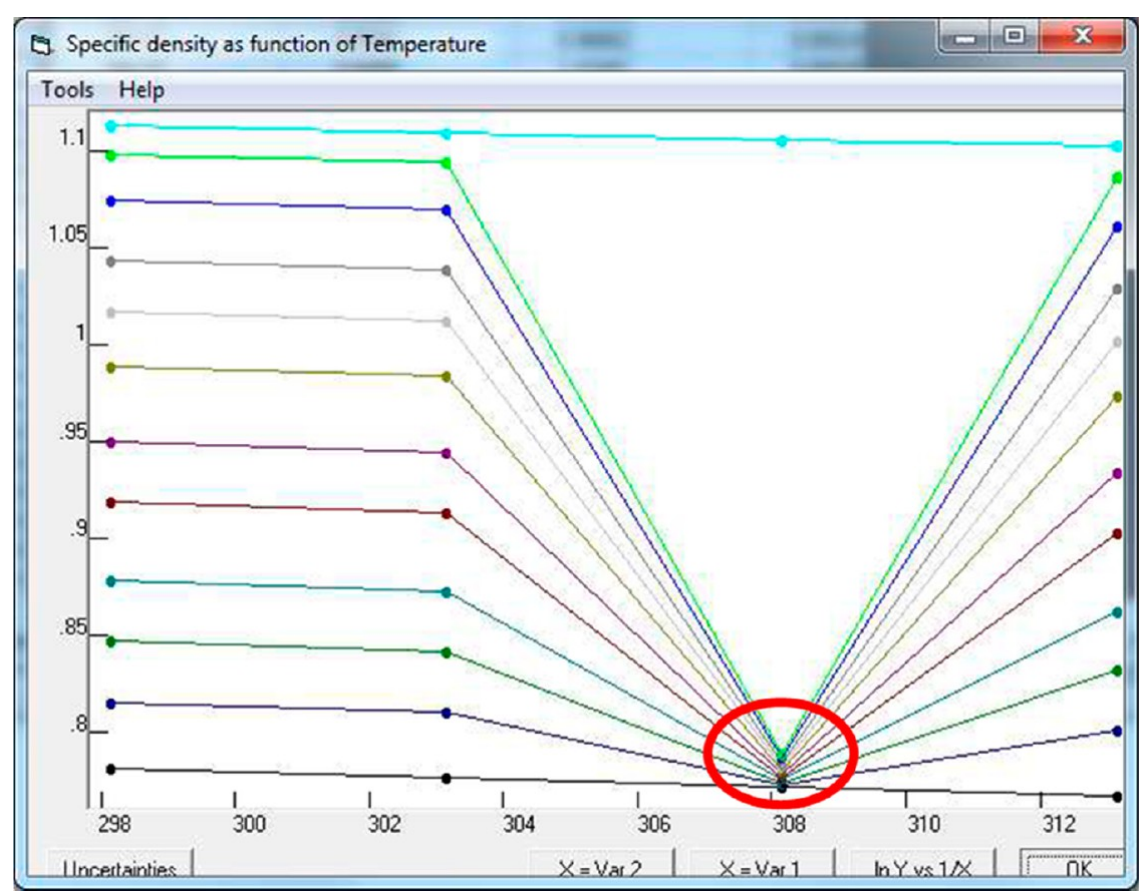

Figure 12. Densities (in $\mathrm{kg} \cdot \mathrm{dm}^{-3}$ ) for a binary system involving two alcohols are shown as a function of temperature (in $\mathrm{K}$ ) for 12 isopleths. Anomalous submitted data are circled.

(Note: It is always possible to publish new experimental data that are inconsistent with the existing literature, but to do this, uncertainties for the new measurements should be well established and validated with measurements on reference systems, whenever possible, and the discrepancies should be discussed by the authors, with justifications, as feasible.) Well characterized reference systems with which an apparatus can be tested are relatively rare, particularly for phase equilibrium studies, and an IUPAC project has been initiated to address this problem. 54
The third problem type listed in Figure 9, "Property definition problems," involves ambiguities in metadata that make appropriate application of the experimental numerical data impossible. These can include missing variables (e.g., a density with no associated temperature), property values without clear attribution (i.e., it cannot be determined if the data were measured directly, derived from other measurements, abstracted from the literature, estimated, etc.), poorly defined compositions (e.g., "molalities" for a particular species in a ternary system without specification of the associated solvent), and others. 
The fourth problem type in Figure 9, "typographical errors," represents those errors that were clearly introduced during manuscript preparation. In modern manuscripts, number transpositions are relatively rare because numerical values are transferred electronically, but large scale errors, in which entire columns of numbers are wrong, are common. An example is given in Figure 12, where densities for the system (propan-2-ol + diethylene glycol) are shown as a function of temperature for twelve isopleths. (The IUPAC name for diethylene glycol is 2,2'oxidiethanol.) A typographical problem affecting most data at the temperature $T=308.15 \mathrm{~K}$ is apparent. These data were fixed by the author and the article was later published.

The fifth common problem involves the reporting of compositions in volume-based units, such as molarity, mass of solute per volume, or volume fraction. Such compositions are awkward to convert to mole fraction because the required densities may be unavailable. Also, some authors report molarities for solutions made under unknown conditions, and then they report properties for those solutions as a function of temperature. Because the volume of the solution changes with temperature, the molarity necessarily does as well. The 2012 Guidelines $^{7}$ recommend that compositions be reported as mole fraction, mass fraction, or molality with a defined solvent, and this recommendation is enforced in the NIST-Journal cooperation.

The final problem type in Figure 9, "other," includes those related to ambiguous compound names, missing experimental method descriptions, unreported experimental data, incomplete sample descriptions, and other miscellaneous problems. The most common of these is the failure to provide a numerical purity for a sample studied, rather than an ill-defined "grade" provided by the chemical manufacturer.

\section{CONCLUSIONS AND FUTURE DEVELOPMENT}

1. The accelerated growth of scientific and technical data within the last 20 years makes it essential to establish data validation procedures outside of the traditional peer review process. Success of these efforts depends on broad involvement of all stakeholders.

2. A global communication and data validation process has been developed for the field of thermophysical properties through cooperation between NIST and five major journals. Although data evaluation is a complex and multifaceted problem, development of efficient software tools has allowed the process to be become rapid and routine.

3. It was found that approximately one-third of articles reporting experimental thermophysical properties contained erroneous (or incomplete) numerical and metadata information, even after peer review. This result was common for all of the cooperating journals, and the developed procedures allowed elimination of these errors before publication.

4. Development of the online ThermoML Archive of published experimental data dramatically shortens the time for delivery of validated data from experimentalists to users from months or years to a few days. Scientists and engineers worldwide have unrestricted access to the archived data files, which can be converted to a format suitable for a particular application by use of either the ThermoML Opener or other specifically designed ThermoML "reader" software. ${ }^{36}$

5. In future work, refinement and expansion of the modeling and prediction tools in the NIST ThermoData Engine
(TDE) will continue at NIST, and these improvements will directly benefit the prepublication data checking that is the core of the NIST-Journal cooperation. Also, the journal support Web sites provide a communication mechanism that can be continuously enhanced and refined. Additional guidance for authors in the estimation of uncertainties is planned.

\section{APPENDIX: ESTIMATION OF UNCERTAINTY FOR DENSITIES AND THE CONTRIBUTION OF SAMPLE IMPURITY}

The measurement of density for pure compounds and mixtures is one of the most often reported properties in the literature, particularly since the development of commercial vibrating U-tube densimeters. In these instruments, the oscillation frequency of a U-tube is related to the density of the fluid that it contains, and absolute values of density are obtained through calibration with a fluid of known density, typically water. The high sensitivity and ease-of-use of these instruments have made them popular not only for studies of density but also as analytical tools for phase equilibrium studies where density-composition calibration curves allow determination of phase compositions. Uncertainty claims made by manufacturers can be very small and are generally given without qualification. For example, one manufacturer reports an "accuracy" to the GUM, ${ }^{17}$ accuracy is conceptual and does not have a numerical value. For the sake of the discussion here, this accuracy is assumed to correspond approximately to a relative standard uncertainty $u_{\mathrm{r}}$ of 0.000005 . A problem arises when authors assume that the "accuracy" stated by the manufacturer is identical to the expanded uncertainty to be reported with their measurement results.

Relative uncertainties $u_{\mathrm{r}}$ for critically evaluated densities of water ${ }^{56} \rho$ are small (typically, $u_{\mathrm{r}}(\rho)=0.00001$ to 0.0002 ), and are very small for liquid water at ambient pressure $\left(u_{\mathrm{r}}(\rho)=\right.$ $0.000001)$. The density of water is known sufficiently well to support the uncertainty claims of the manufacturer only for water near ambient pressure. In addition, there is the underlying assumption that the measurement model holds (i.e., the relationship between vibrational frequency of the U-tube and density). At high temperatures and pressures, uncertainty for the density of water must be considered. A detailed plot of uncertainties for the density of water as a function of temperature and pressure is given on page 434 of ref 56.

The most important consideration that is overlooked by most authors is the purity of the sample measured. Reported measurements on samples of mole fraction purity 0.99 and less are very common, and these reports typically cite the uncertainty stated by the instrument manufacturer as the standard uncertainty for their measured densities. Furthermore, the identity of the impurities is very rarely known. A rough estimate of the contribution of sample impurity to the uncertainty can be made by assuming (1) the impurity has a density that is $10 \%$ different from the sample of interest and (2) the excess volume is zero for the mixture of the impurity and the sample of interest. Based on these assumptions, the relative uncertainty for the density of a sample of 0.99 mol fraction purity would be $u_{\mathrm{r}}(\rho)=$ 0.001 or 200 times larger than the value stated by the manufacturer. The assumption of zero excess volume results in a linear relationship between the relative uncertainty $u_{\mathrm{r}}(\rho)$, the sample purity $x_{\mathrm{s}}$, and the assumed fractional density difference $\xi$ between the compound of interest and the impurity. 


$$
u_{\mathrm{r}}(\rho)=\xi \cdot\left(1-x_{\mathrm{s}}\right)
$$

If the assumed difference in density between the sample of interest and the impurity is $10 \%$, then $\xi$ is 0.1 . This is only a rough estimate and is provided to show the pitfall of simply reporting the uncertainty claimed by the manufacturer. Many chemical systems have substantial excess volumes, which would cause larger shifts of density with impurity.

In the long term, we believe that undergraduate and graduatelevel educational institutions are the key venues in which to address the problem of poor understanding of the concept of uncertainty for physical properties. Recent work by Kim et al. ${ }^{57}$ seeks to begin to provide the resources needed for this task.

\section{AUTHOR INFORMATION}

\section{Corresponding Author}

*E-mail: chirico@boulder.nist.gov.

\section{Notes}

The authors declare no competing financial interest.

\section{ACKNOWLEDGMENTS}

The authors express their appreciation to the journal publishers and staff (past and present) of the cooperating organizations (Jeffrey Mullins, Clay Burgett, and Susan King of the American Chemical Society Publications; Ella Chen, Helen Habernickel, and Michiel Thijssen of Elsevier B. V.; and Kyesha Hammond of Springer) for their keen interest in and support of this project. Their efforts have been essential to the success of this work. The authors thank IUPAC (the International Union for Pure and Applied Chemistry) for partial support of four projects related to this work; IUPAC Guidelines for Reporting of Phase Equilibrium Measurements (IUPAC project 2007-024-2-100), XML-Based IUPAC Standard for Experimental, Predicted, and Critically Evaluated Thermodynamic Property Data Storage and Capture (ThermoML) (IUPAC project 2002-055-3-024), Extension of ThermoML: The IUPAC Standard for Thermodynamic Data Communications (IUPAC project 2007-039-1-024), and the current project Recommended Reference Materials for Phase Equilibrium Studies (IUPAC project 2011-037-2-100). The project described in this article would be impossible to conduct without the participation of thousands of authors contributing feedback for continuous improvement of the data validation process. Products or companies named here are cited only in the interest of complete technical description and neither constitute nor imply endorsement by NIST or by the U.S. government. Other products may be found to serve as well.

\section{REFERENCES}

(1) Marsh, K. N. New process for data submission and dissemination. J. Chem. Eng. Data 2003, 48, 1.

(2) Electronic data submission to the NIST Thermodynamics Research Center. J. Chem. Thermodyn. 2004, 36, iv.

(3) Electronic data submission to NIST Thermodynamics Research Center. Fluid Phase Equilib. 2004, 226, v.

(4) Electronic data submission to NIST Thermodynamics Research Center. Thermochim. Acta 2004, 421, 241.

(5) Haynes, W. M. Electronic data submission for the International Journal of Thermophysics. Int. J. Thermophys. 2005, 26, 307.

(6) Cummings, P. T.; de Loos, T.; O’Connell, J. P.; Haynes, W. M.; Friend, D. G.; Mandelis, A.; Marsh, K. N.; Brown, P. L.; Chirico, R. D.; Goodwin, A. R. H.; Wu, J.; Weir, R. D.; Trusler, J. P. M.; Pádua, A.; Rives, V.; Schick, C.; Vyazovkin, S.; Hansen, L. D. Joint statement of editors of journals publishing thermophysical property data: Process for article submission for The Journal of Chemical Thermodynamics, Fluid Phase
Equilibria, International Journal of Thermophysics, Thermochimica Acta, and Journal of Chemical Engineering Data. Fluid Phase Equilib. 2009, 276, 165-166; Int. J. Thermophys. 2009, 30, 371-373; J. Chem. Eng. Data 2009, 54, 2-3; J. Chem. Thermodyn. 2009, 41, 575-576; Thermochim. Acta 2008, 484, vii-viii.

(7) Chirico, R. D.; De Loos, T. W.; Gmehling, J.; Goodwin, A. R. H.; Gupta, S.; Haynes, W. M.; Marsh, K. N.; Rives, V.; Olson, J.; Spencer, C.; Brennecke, J. F.; Trusler, J. P. M. Guidelines for reporting of phase equilibrium measurements (IUPAC Recommendations 2012). Pure Appl. Chem. 2012, 84, 1785.

(8) IUPAC. A guide to procedures for the publication of thermodynamic data. Pure Appl. Chem. 1972, 29, 395-408.

(9) Poling, B. E.; Prausnitz, J. M.; O'Connell, J. P. The Properties of Gases and Liquids, 5th ed.; McGraw Hill: New York, 2001; Ch. 8.

(10) Merriam-Webster: An encyclopaedia Britannica company. http://www.merriam-webster.com/dictionary/. Oxford Dictionaries. http://oxforddictionaries.com/ (accessed Apr. 1, 2013).

(11) Taylor, B. N.; Kuyatt, C. E. Guidelines for the evaluation and expression of uncertainty in NIST measurement results; NIST Technical Note 1297; NIST: Gaithersburg, MD, 1994.

(12) Larsen, P. O.; von Ins, M. The rate of growth in scientific publication and the decline in coverage provided by Science Citation Index. Scientometrics 2010, 84, 575-603.

(13) Dong, Q.; Chirico, R. D.; Yan, X.; Hong, X.; Frenkel, M. Uncertainty reporting for experimental thermodynamic properties. $J$. Chem. Eng. Data 2005, 50, 546-550.

(14) Moldover, M. R. Visual observation of the critical temperature and density: $\mathrm{CO}_{2}$ and $\mathrm{C}_{2} \mathrm{H}_{4}$. J. Chem. Phys. 1974, 61, 1766-1778.

(15) Guide to the Expression of Uncertainty in Measurement; International Organization for Standardization: Geneva, Switzerland, 1993. This Guide was prepared by ISO Technical Advisory Group 4 (TAG 4), Working Group 3 (WG 3). ISO/TAG 4 has as its sponsors the BIPM, IEC, IFCC (International Federation of Clinical Chemistry), ISO, IUPAC (International Union of Pure and Applied Chemistry), IUPAP (International Union of Pure and Applied Physics), and OIML. Although the individual members of WG 3 were nominated by the BIPM, IEC, ISO, or OIML, the Guide is published by ISO in the name of all seven organizations.

(16) U.S. Guide to the Expression of Uncertainty in Measurement, ANSI/ NCSL Z540-2-1997; NCSL International: Boulder, CO, 1997; ISBN 158464-005-7.

(17) GUM: Guide to the Expression of Uncertainty in Measurement. http://www.bipm.org/en/publications/guides/gum.html (accessed Apr. 1, 2013).

(18) VIM3: International Vocabulary of Metrology. http://www.bipm. org/en/publications/guides/vim.html (accessed Apr. 1, 2013).

(19) Chirico, R. D.; Frenkel, M.; Diky, V. V.; Marsh, K. N.; Wilhoit, R. C. ThermoML-an XML-based approach for storage and exchange of experimental and critically evaluated thermophysical and thermochemical property data. 2. Uncertainties. J. Chem. Eng. Data 2003, 48, 13441359.

(20) Frenkel, M.; Chirico, R. D.; Diky, V. V.; Marsh, K. N.; Dymond, J. H.; Wakeham, W. A.; Stein, S. E.; Königsberger, E.; Goodwin, A. R. H. XML-based IUPAC standard for experimental, predicted, and critically evaluated thermodynamic property data storage and capture (ThermoML): IUPAC recommendations 2006. Pure Appl. Chem. 2006, 78, 541-612.

(21) Frenkel, M.; Chirico, R. D.; Diky, V. V.; Brown; Dymond, J. H.; Goldberg, R. N.; Goodwin, A. R. H.; Heerklotz, H.; Königsberger, E.; Ladbury, J. E.; Marsh, K. N.; Remeta, D. P.; Stein, S. E.; Wakeham, W. A.; Williams, P. A. Extension of ThermoML: The IUPAC standard for thermodynamic data communications (IUPAC Recommendations 2011). Pure Appl. Chem. 2011, 83, 1935-1967.

(22) Nature's peer review debate. http://www.nature.com/nature/ peerreview/debate/ (accessed Apr. 1, 2013).

(23) Lee, K.; Bero, L. Increasing accountability. What authors, editors, and reviewers should do to improve peer review. Nature 2006, 10, 1038/ nature05007. 
(24) Frenkel, M.; Chirico, R. D.; Diky, V. V.; Dong, Q.; Frenkel, S.; Franchois, P. R.; Embry, D. L.; Teague, T. L.; Marsh, K. N.; Wilhoit, R. C. ThermoML: An XML-based approach for storage and exchange of experimental and critically evaluated thermophysical and thermochemical property data. 1. Experimental data. J. Chem. Eng. Data 2003, 48, 2-13. (25) ThermoML Archive of Published Experimental Data. http://trc. nist.gov/ThermoML.html (accessed Apr. 1, 2013).

(26) Diky, V. V.; Chirico, R. D.; Wilhoit, R. C.; Dong, Q.; Frenkel, M. Windows-based guided data capture software for mass-scale thermophysical and thermochemical property data collection. J. Chem. Inf. Comput. Sci. 2003, 43, 15-24.

(27) Frenkel, M.; Chirico, R. D.; Diky, V.; Muzny, C. D.; Dong, Q.; Marsh, K. N.; Dymond, J. H.; Wakeham, W. A.; Stein, S. E.; Königsberger, E.; Goodwin, A. R. H.; Magee, J. W.; Thijssen, M.; Haynes, W. M.; Watanasiri, S.; Satyro, M.; Schmidt, M.; Johns, A. I.; Hardin, G. R. New global communication process in thermodynamics: Impact on quality of published experimental data. J. Chem. Inf. Model. 2006, 46, 2487-2493.

(28) Frenkel, M.; Chirico, R. D.; Diky, V.; Yan, X.; Dong, Q.; Muzny, C. D. ThermoData Engine (TDE): Software implementation of the dynamic data evaluation concept. J. Chem. Inf. Model. 2005, 45, 816838.

(29) Diky, V.; Muzny, C. D.; Lemmon, E. W.; Chirico, R. D.; Frenkel, M. ThermoData Engine (TDE): Software implementation of the dynamic data evaluation concept. 2: Equations of state on demand and dynamic updates over the Web. J. Chem. Inf. Model. 2007, 47, 17131725 .

(30) Diky, V.; Chirico, R. D.; Kazakov, A. F.; Muzny, C. D.; Frenkel, M. ThermoData Engine (TDE): Software implementation of the dynamic data evaluation concept. 3: Binary mixtures. J. Chem. Inf. Model. 2009, 49, 503-517.

(31) Diky, V.; Chirico, R. D.; Kazakov, A. F.; Muzny, C. D.; Frenkel, M. ThermoData Engine (TDE): Software implementation of the dynamic data evaluation concept. 4: Chemical reactions. J. Chem. Inf. Model. 2009, 49, 2883-2896.

(32) Diky, V.; Chirico, R. D.; Kazakov, A. F.; Muzny, C. D.; Magee, J. W.; Abdulagatov, I.; Kang, J. W.; Kroenlein, K.; Frenkel, M. ThermoData Engine (TDE): Software implementation of the dynamic data evaluation concept. 5. Experiment planning and product design. J. Chem. Inf. Model. 2011, 51, 181-194.

(33) Diky, V.; Chirico, R. D.; Muzny, C. D.; Kazakov, A. F.; Kroenlein, K.; Magee, J. W.; Abdulagatov, I.; Kang, J. W.; Frenkel, M. ThermoData Engine (TDE): Software implementation of the dynamic data evaluation concept. 7. Ternary mixtures. J. Chem. Inf. Model. 2012, 52, 260-276.

(34) Diky, V.; Chirico, R. D.; Muzny, C. D.; Kazakov, A. F.; Kroenlein, K.; Magee, J. W.; Abdulagatov, I.; Kang, J. W.; Gani, R.; Frenkel, M. ThermoData Engine (TDE): Software implementation of the dynamic data evaluation concept. 8. Properties of material streams and solvent design. J. Chem. Inf. Model. 2013, 53, 249-266.

(35) Kazakov, A.; Muzny, C. D.; Kroenlein, K.; Diky, V.; Chirico, R. D.; Magee, J. W.; Abdulagatov, I. M.; Frenkel, M. NIST/TRC SOURCE data archival system: The next-generation data model for storage of thermophysical properties. Int. J. Thermophys. 2012, 33, 22-33.

(36) Frenkel, M. Global information systems in science: Application to the field of thermodynamics. J. Chem. Eng. Data 2009, 54, 2411-2428.

(37) (a) Wilhoit, R. C.; Marsh, K. N. Future directions for data compilation. Int. J. Thermophys. 1999, 20, 247-255. (b) Frenkel, M. Dynamic compilation: A key concept for future thermophysical data evaluation. In Forum 2000: Fluid Properties for New Technologies s Connecting Virtual Design with Physical Reality; Rainwater, J. C., Friend, D. G., Hanley, H. J. M., Harvey, A. H., Holcomb, C. D., Laesecke, A., Magee, J. W., Muzny, C., Eds.; NIST Special Publication 975; NIST: Gaithersburg, MD, 2001; pp 83-84.

(38) Berman, H. M.; Westbrook, J.; Feng, Z.; Gilliland, G.; Bhat, T. N.; Weissig, H.; Shindyalov, I. N.; Bourne, P. E. The Protein Data Bank. Nucleic Acids Res. 2000, 28, 235-242. See also http://www.rcsb.org/ pdb/ (accessed Apr. 1, 2013)
(39) Cambridge Crystallographic Data Centre. http:/www.ccdc.cam. ac.uk/products/csd/ (accessed Apr. 1, 2013).

(40) ThermoML Opener: A tool for direct viewing of ThermoML files. http://www.trc.nist.gov/ThermoML_Opener.html (accessed Apr. 1, 2013).

(41) Brennecke, J. F.; Goodwin, A. R. H.; Mathias, P.; Wu, J. New procedures for articles reporting thermophysical properties. J. Chem. Eng. Data 2011, 56, 4279.

(42) Weir, R. D.; Trusler, J. P. M.; Pádua, A. New procedures for articles reporting thermophysical properties. J. Chem. Thermodyn. 2011, 43, 1305.

(43) Cummings, P. T.; De Loos, T. W.; O'Connell, J. P. New procedures for articles reporting thermophysical properties. Fluid Phase Equilib. 2011, 307, iv.

(44) Rives, V.; Schick, C.; Vyazovkin, S. New procedures for articles reporting thermophysical properties. Thermochim. Acta 2011, 521, 1.

(45) Haynes, W. M.; Friend, D. G.; Mandelis, A. Editorial: New procedures for articles reporting thermophysical properties. Int. J. Thermophys. 2011, 32, 1999.

(46) Kroenlein, K.; Diky, V.; Muzny, C. D.; Chirico, R. D.; Magee, J. W.; Frenkel, M. ThermoLit: NIST literature report builder for thermophysical and thermochemical property measurements. NIST Standard Reference Database 171. http://trc.nist.gov/thermolit/ (accessed Apr 1, 2013).

(47) Data Table and Sample Description Requirements: Journal of Chemical and Engineering Data, http://trc.nist.gov/JCED-Support.html; The Journal of Chemical Thermodynamics, http://trc.nist.gov/JCTSupport.html; Fluid Phase Equilibria, http://trc.nist.gov/FPE-Support. html; Thermochimica Acta, http://trc.nist.gov/TCA-Support.html; International Journal of Thermophysics, http://trc.nist.gov/IJT-Support. html (accessed Apr. 1, 2013).

(48) ThermoLit: Video Demonstrations. http://trc.nist.gov/ thermolit/main/video home.html (accessed Apr. 1, 2013).

(49) ThermoLit: Scope and Applicability. http://trc.nist.gov/ thermolit/main/home.html\#questions (accessed April 1, 2013).

(50) Kroenlein, K.; Diky, V.; Muzny, C. D.; Chirico, R. D.; Magee, J. W.; Frenkel, M. ThermoPlan: Experiment planning and coverage evaluation aid for thermophysical property measurements. NIST Standard Reference Database 167. http://trc.nist.gov/thermoplan/ main/home.html (accessed Apr. 1, 2013).

(51) Kang, J. W.; Diky, V.; Chirico, R. D.; Magee, J. W.; Muzny, C. D.; Abdulagatov, I.; Kazakov, A. F.; Frenkel, M. A quality assessment algorithm for vapor-liquid equilibrium data. J. Chem. Eng. Data 2010, $55,3631-3640$

(52) Kang, J. W.; Diky, V.; Chirico, R. D.; Magee, J. W.; Muzny, C. D.; Abdulagatov, I.; Kazakov, A. F.; Frenkel, M. A new method for evaluation of UNIFAC interaction parameters. Fluid Phase Equilib. 2011, 309, 68-75.

(53) Frenkel, M. Thermophysical and thermochemical properties ondemand for chemical process and product design. Comput. Chem. Eng. 2011, 35, 393-402.

(54) IUPAC Project 2011-037-2-100: Recommended Reference Materials for Phase Equilibrium Studies. http://www.iupac.org/nc/ home/projects/project-db/project-details.html?tx_wfqbe pi1[project_nr]=2011-037-2-100 (accessed Apr. 1, 2013).

(55) Anton Paar Density Meters: DMA Generation M. http://www. anton-paar.com/Density-Meters-DMA-Generation-M/DensityMeter $/ 60$ Corporate en?product id $=144 \#$ Specifications (accessed Apr. 1, 2013).

(56) Wagner, W.; Pruss, A. The IAPWS formulation 1995 for the thermodynamic properties of ordinary water substance for general and scientific use. J. Phys. Chem. Ref. Data 2002, 31, 387-535.

(57) Kim, S. H.; Kang, J. W.; Kroenlein, K.; Magee, J. W.; Diky, V.; Muzny, C. D.; Kazakov, A. F.; Chirico, R. D.; Frenkel, M. Online data resources in Chemical Engineering Education: Impact of the uncertainty concept for thermophysical properties. Chem. Eng. Educ. 2013, 47, 4857. 